Portland State University

PDXScholar

1989

\title{
Making sense of America : a phenomenological analysis of Chinese nationals' interactions in the U.S.
}

Donna Marie EcElroy

Portland State University

Follow this and additional works at: https://pdxscholar.library.pdx.edu/open_access_etds

Part of the International and Intercultural Communication Commons

Let us know how access to this document benefits you.

\section{Recommended Citation}

EcElroy, Donna Marie, "Making sense of America : a phenomenological analysis of Chinese nationals' interactions in the U.S." (1989). Dissertations and Theses. Paper 4101.

https://doi.org/10.15760/etd.5985

This Thesis is brought to you for free and open access. It has been accepted for inclusion in Dissertations and Theses by an authorized administrator of PDXScholar. Please contact us if we can make this document more accessible: pdxscholar@pdx.edu. 
AN ABSTRACT OF THE THESIS OF Donna Marie McElroy for the Master of Science in speech Communication presented November $16,1989$.

Title: Making Sense of America: A Phenomenological Analysis of Chinese Nationals' Interactions in the U.S.

APPROVED BY THE MEMBERS OF THE THESIS COMMITTEE:
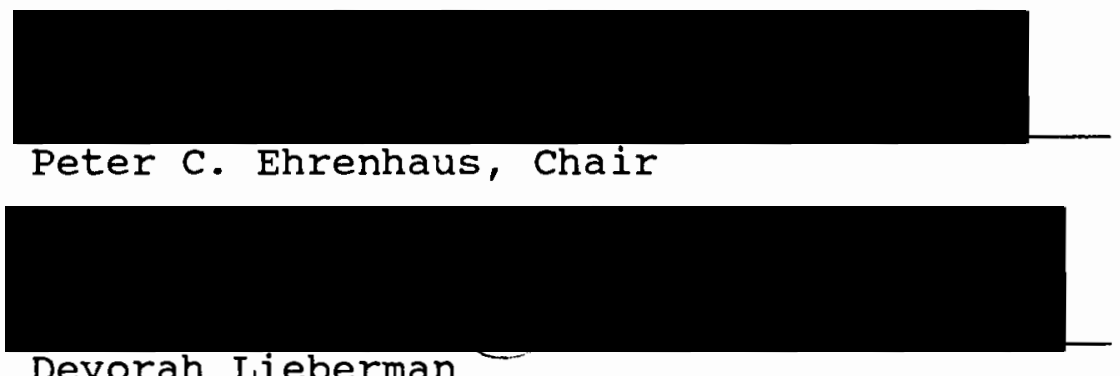

Devorah Lieberman

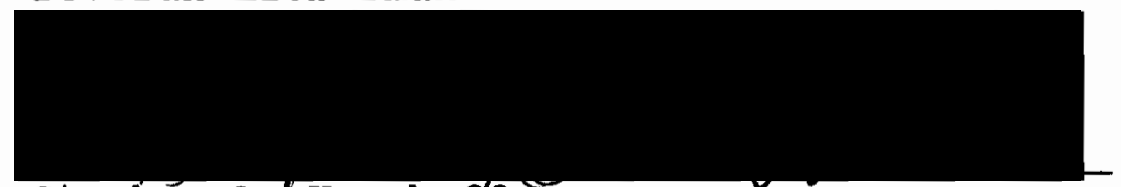

Stephen A.I Kosokoflf

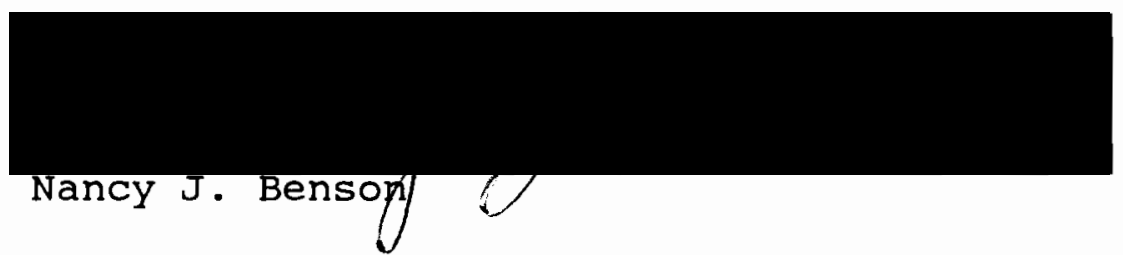

This thesis systematically explores the interactive experiences of Chinese students and scholars in the U.S. Specifically, the research asks: How do Chinese students and scholars (from the People's Republic of China) interpret their interactions in the U.S., and how do their interpretations change over their tenure in the U.S.? 
Research on general issues of cultural experience and adjustment is reviewed. Further, meta-theoretical issues in the study of cultural experience and adaptation are addressed. These issues provide a background for both the phenomenological grounding of this study and the qualitative approach used for data collection and analysis.

Chinese students and scholars were interviewed. Interviews were tape recorded. The interview schedule was structured around issues of obligation, prohibition, permissibility, and preference for modes of interpretation and action. More specific probing followed respondents' comments. Using techniques of interpretive analysis, transcripts from the interviews were analyzed for emergent issues, patterns, and categories.

Data from the transcripts coalesced around the following topic or issue areas: perceptions of America and Americans, critical incidents or issues, adaptation (which addresses change during a respondent's U.S. tenure), the impenetrable and, most notably, relationships. In examining respondents' expectations for prohibited, obligated, permitted, and preferred actions, a pattern appeared in which respondents noted discomfort in the lack of obligation in personal relationships in the U.S., and a strong sense of prohibition against expressing obligation in their relationships with Americans. For a number of respondents, obligation appeared to solidify relationships, and the 
absence of obligation fostered an often painful sense of non-connectedness. The absence of obligation in relationships in the U.S., and the resulting feeling of non-connectedness, appears to create other dilemmas for the chinese student and scholar: How to get information necessary to function in the U.S., how to know or feel close to Americans, and how to relate to fellow chinese in the U.S. Implications for intercultural training and advising are discussed. Finally, in view of the study's limitations and strengths, the thesis concludes with suggestions for further research. 


\title{
MAKING SENSE OF AMERICA:
}

A PHENOMENOLOGICAL ANALYSis OF CHINESE NATIONALS' INTERACTIONS IN THE U.S.

$$
\text { by }
$$

DONNA MARIE MCELROY

A thesis submitted in partial fulfillment of the requirements for the degree of

\author{
MASTER OF SCIENCE \\ in \\ SPEECH COMMUNICATION
}

Portland State University

1990 
TO THE OFFICE OF GRADUATE STUDIES:

The nembers of the committee approve the thesis of Donna Marie McElroy presented November 16, 1989.

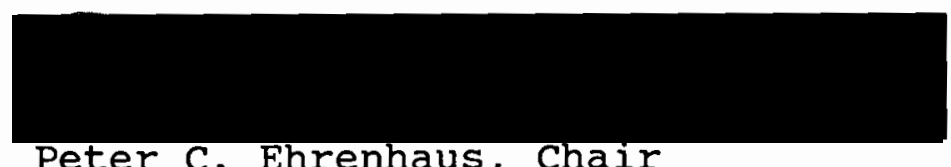

Peter C. Ehrenhaus, Chair

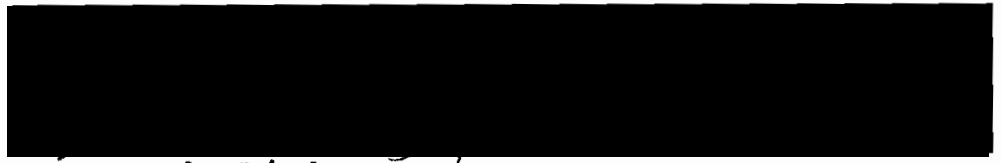

Devorah Lieberman
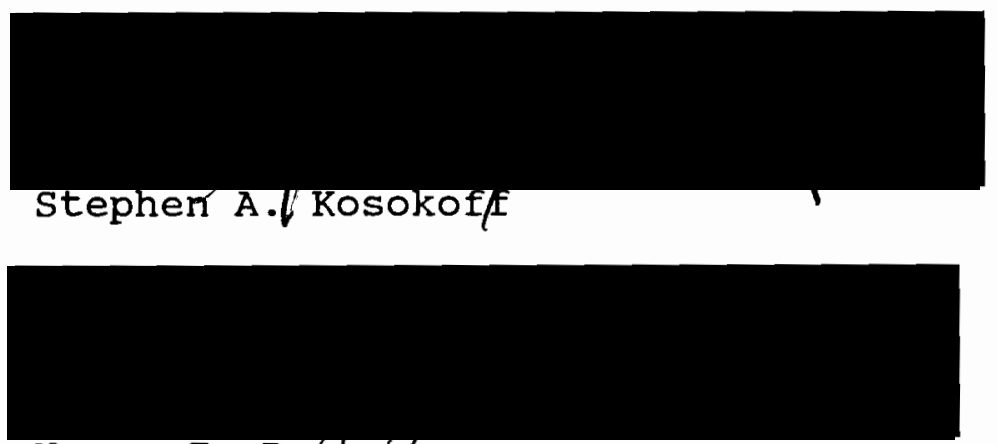

Nancy J. Bephsod

\section{APPROVED:}

Theodore G. Grove, Chair

Department of Speech Communication

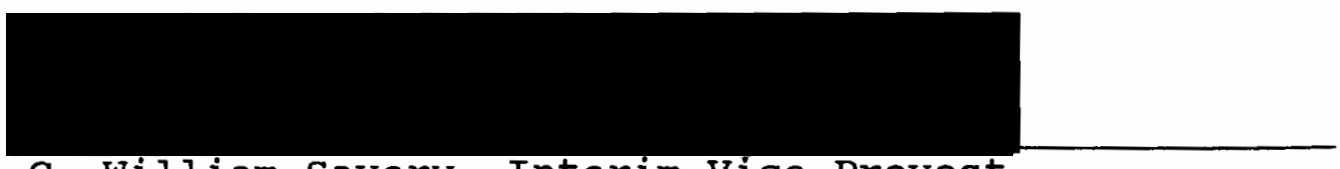

C. William Savery, Interim Vice Provost

for Graduate Studies and Research 


\section{DEDICATED TO}

my aunts, Ellen and Merle, my sisters, Barbara and Mary, and my father 


\section{ACKNOWLEDGEMENTS}

It is with deep gratitude and much warmth and respect that I thank all of the participants in this study who so generously shared their thoughts and experiences with me. Also, I would like to thank Liu Junhe for his valued assistance and counsel.

special thanks to my fellow graduate students in the Department of speech Communication for their intelligence and warmth, especially Noriko, Zhijian, and Hyla.

Much appreciation to Milton and Janet Bennett, Dorothy Sermol, Devorah Lieberman, Steve Kosokoff, Nancy Benson, Larry Steward, and, particularly, Peter Ehrenhaus for introducing me to new ways of viewing the social world, for encouragement, and for guidance.

Thanks to Raul Martinez and Irene Curtis for their encouragement, support, and willingness to share their experiences in working with international students.

Thanks to my friends and neighbors for their affection and support, to Shawna for her companionship and devotion, and, most of all, to steve and Lindsey for being so much more than I ever could have imagined. 
TABLE OF CONTENTS

PAGE

DEDICATION • • • • • • • • • • • • • • • • • •

ACKNOWLEDGEMENTS . . . . . . . . . . . . . . . iv

CHAPTER

I

INTRODUCTION • • • . . . . . . . . . 1

The Driving Force Behind this Investi-

gation . . . . . . . . . . . . . 1

Chinese students in the U.S. . . . . 2

Cultural Adjustment: Issues and

Research . . . . . . . . . . . 4

Cultural Adjustment from the Chinese

Student's Perspective.. . . . . . 5

II CULTURAL EXPERIENCE AND ADJUSTMENT • • • . 7

Introduction . . . . . . . . . . 7

The Study of Cultural Experience and

Adaptation ........... . . . 7

General Issues of cultural Adaptation

Cultural Characteristics: China and the U.S.

Factors which may Influence the Cultural Adaptation of Chinese Students in the U.S.

Studies which Bear Upon the Adaptation of Chinese students in the U.S.

Meta-theoretical Issues in the study of Cultural Experience and Adaptation . . 20 
World View I and World View II

The Action Tradition and the Role of Normative Force

Rules: The Basis for Action and Interpretation

General Research Questions . . . . . 27

Specific Research Questions . . . . . 28

III METHODOLOGY • . • . . • . . . . . . . 31

Phenomenology as a Framework . . . . . 31

Qualitative Research Methods . . . . 32

Respondents . . . . . . . . . . 35

The Interview Schedule . . . . . . 37

Procedures . . . . . . . . . . . 43

Preliminary Information Given to

Respondents

The Interview

Recording Data

Transcription

Data Analysis

IV DESCRIPTION/ANALYSIS - . • • • • • . . . . 52

Introduction . . . . . . . . 52

orientations .......... 53

Topics/Issues . . . . . . . . . . 57

Perceptions of America and Americans

Generalizations

Characteristics of America

and Americans which

Respondents Value

Characteristics of America

and Americans which

Respondents find

Troublesome 
Relationships

Friends

Parent/Child

Housemates

Male/Female

Student/Professor and

student/Student

Employer/Employee

older/Younger

Neighbors

General Issues of Relationship

Critical Incidents/Issues

Interpretations

Animals

Education and Money

Adaptation

Changes Respondents have observed in Themselves

No Change

Refined Understandings of U.S. Culture

Direct and Indirect Communication: Does "no" mean "yes?"

The Impenetrable: Enduring Confusion or Problems

A Chance of a Lifetime Respondents' Advice to Chinese

Patterns: Prohibited, obligated,

Permitted, and Preferred Actions . . . 98

Lack of obligation and the Presence of Prohibition as Patterns

Patterns of Reasoning and Action:

Chinese and Scholars' Intercultural

Experience. . . . . . . . . . 109

Introduction . . . . . . . . . . 111

Dilemmas of Non-connectedness . . . . 111 
How to get Information Necessary to Function in the U.S.

How to know or Feel close to Americans

How to Relate to Fellow Chinese

In the U.S.

Non-connectedness: A Dominant

Interpersonal Theme in the U.S. . . . 118

Implications for Intercultural

Training and Advising. . . . . 120

orientation Programs

Limitations of this study . . . . 125

Strengths and Benefits of Using

Naturalistic Research Methods . . 126

Future Directions . . . . . . 128

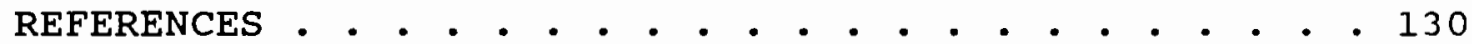

APPENDICES . . . . . . . . . . . . . . . 135

A LETTER TO POTENTIAL RESPONDENT . . . . . . 135

B INTERVIEW SCHEDULE . . . . . . . . . 137

C INFORMED CONSENT FORM . . . . . . . . . 141

D FACE SHEET . . . . . . . . . . . 143 
CHAPTER I

INTRODUCTION

THE DRIVING FORCE BEHIND THIS INVESTIGATION

This study was sparked by the convergence of a longstanding interest in Chinese beliefs and practices and my recent experiences with Chinese nationals studying or teaching in the U.S. Literature on chinese cultural characteristics seemed inadequate for understanding behavior and attitudes that I observed in interactions with Chinese nationals at U.S. universities. These students and scholars, for the most part, seemed exceptionally independent, selfsufficient, adaptable, and indivdualistic--traits which have been given little attention in literature describing Chinese cultural characteristics (see Cultural Characteristics: China and the U.S., pp. 12-14).

As I pondered why the behavior and attitudes of these young Chinese students and scholars might appear so different from the "Chinese character" as conveyed in cultural descriptions, I entertained a number of possibilities: Perhaps Chinese nationals who come to the United states to teach or study are quite different from the typical chinese person, and, therefore, deviate from accepted norms for 
cultural characteristics. Perhaps the powerful events in China in recent decades have significantly modified the Chinese character. On the other hand, perhaps it is not the visiting Chinese who are straying from the traditional notion of the Chinese character, but rather that cultural profiles focus on generalizations which are, by necessity, simplistic--lacking nuance and the rich complexity of personality. In addition, perhaps I have misinterpreted the meaning of Chinese nationals' attitudes and behaviors because of my own cultural biases.

In an attempt to sort out these and other possibilities, I decided to talk directly with chinese students and scholars. I felt that through systematic interaction, it would be possible to extend my understanding of chinese students' and scholars' attitudes and behaviors beyond both the "Chinese character" of cultural literature and some of my own cultural biases. It was with this intent that the study was born.

CHINESE STUDENTS IN THE U.S.

According to the 1987-88 edition of open Doors (Institute of International Education, 1988), Chinese students have been the fastest growing group of foreign students in the United States during the past five years. In 1987-88 students from the People's Republic of China totaled 25,200 , a jump of 26 percent from the previous year. 
In his 1988 book, Chinese students in America, Orleans discusses some of the reasons for Chinese students' attraction to the U.S.:

The Chinese 'magnet' is not new. Of the millions who migrated in the past hundred years, the overwhelming proportion left not because of a special attraction for or the 'pull' of foreign lands, but because of the 'push' created by the inordinately difficult economic and political conditions in their homeland. (p. 44)

He brings this sense of "push" up to date as he discusses the absence of opportunity in China for scientists, engineers, those interested in doing basic research, and those interested in professional freedom of expression in the social sciences, arts, and humanities. Moving beyond professional opportunities, there is the "inevitable lure of income and life-style to which all Chinese students can aspire in the United States" (p. 45).

Orleans reminds us that:

The historical and cultural factors which translate into a traditional attachment to the motherland may be less visible among the much more sophisticated Chinese students now in the United states, but for most of them, nationalism and the desire to be part of a chinese renaissance are still present. . . A survey of Chinese students in the U.S. showed the overwhelming proportion intend to return home and, according to this survey \{done in 1986\}, the main reason for this decision is 'because they are chinese'. (p. 44)

Although the number of Chinese students and scholars in the U.S. has grown steadily in recent years, it is unlikely that this will continue given the reaction of the Chinese government to the spring 1989 democracy 
demonstrations. In fact, it is likely that fewer students and scholars will be permitted to study in the U.S. The number of Chinese students and scholars in the U.S. may not grow substantially in the near future; however, issues of adjustment have become significantly exacerbated because of the Chinese government's crackdown of pro-democracy demonstrators. Many students fear reprisals if they should return home. Some fear for their families and friends. Others fear their children and spouses will not be permitted to join them in the U.S. Coupled with the distress of potential exile from China, Chinese students and scholars must now deal with the opportunities and losses related to extended or permanent residency in the U.S. Both the U.S. Senate and House of Representatives have bills in process that could provide opportunities for these chinese nationals to extend their legal stays in the U.S. and to be granted permanent resident status. Although the protection that these bills may offer is welcomed by most chinese students and scholars, the thought of abandoning their homeland is very painful.

\section{CULTURAL ADJUSTMENT: ISSUES AND RESEARCH}

What does being chinese mean to these students and scholars? Particularly, what does being a chinese student or teacher in the U.S. mean? Do Chinese students and scholars experience a vastly different culture in the U.S.? And if so, how do they deal with this? Are there "Chinese 
characteristics" that are preciously guarded or freely abandoned? Are there "American characteristics" that are welcomed or rejected? How does cultural adjustment proceed for chinese students and scholars in the U.S.?

Research literature can provide us with some clues as to how cultural adjustment may proceed for the chinese student in America. A number of authors have written about the adjustment process of persons who temporarily or permanently reside in a foreign country. Others have studied the cultural characteristics of Americans and Chinese. Indeed, a few researchers have studied the adjustment process of chinese students in the U.S. (For a glimpse of these works, see pages 18-19.) However, these research findings do not provide us with much direct understanding of the Chinese student experience in the U.S.

What are the adjustment experiences of Chinese students and scholars in the U.S.? This question and those which have been asked earlier can most productively be approached from the perspective of the visiting chinese student and scholar.

CULTURAL ADJUSTMENT FROM THE CHINESE STUDENT'S PERSPECTIVE

Liu (1984) and Wang (1986), Chinese scholars who have lived in the U.S., have each written books which highlight their personal experiences in America. Liu's book, Two Years in the Melting Pot, has become the accepted 
introduction for many chinese students preparing to come to the U.S. While these anecdotal works are useful in understanding the writers' experiences in America, neither are based on systematic study. Despite the recent increase in students (and scholars) from the Peoples Republic of China studying and teaching in the U.S., there is little contemporary writing which gives attention to the thinking and experiences of this particular population. Specifically, there is a need for systematic investigation that explores Chinese students' and scholars' subjective experiences. The present study addresses this need. The task of this thesis is to systematically explore the subjective experience of chinese students and scholars, particularly in terms of the challenges and opportunities they face in adapting to American culture.

This thesis focuses on interpersonal interaction from the perspective of the chinese student or scholar. Specifically, how do Chinese students and scholars (from the People's Republic of China) make sense of and explain their interactions in the U.S.? Moreover, how do their interpretations change over their tenure in the U.S.? These questions are best explained from a phenomenological perspective. The general assumptions which underlie phenomenological inquiry are developed in chapter II. 


\section{CHAPTER II \\ CULTURAL EXPERIENCE AND ADJUSTMENT}

\section{INTRODUCTION}

As pointed out in chapter I, the purpose of this study is to understand how Chinese students and scholars interpret their interactions in the U.S. and how their interpretations may change over time. The literature reviewed in this chapter concentrates on two major areas relevant to this inquiry. The first relates, in large part, to substantive issues of cultural experience and adaptation. The second concerns meta-theoretical issues in the study of cultural experience and adaptation, and it is here that the assumptions which underlie this inquiry are developed. Finally, the study's research questions are presented.

\section{THE STUDY OF CUITURAI EXPERIENCE AND ADAPTATION}

\section{General Issues of cultural Adaptation}

Yoshikawa (1988), in writing about cross-cultural adaptation, describes five stages: contact, disintegration, reintegration, autonomy, and double swing. The first stage, contact, Yoshikawa describes as one in which the person "fails to recognize the new realities" (p. 141). 
Cultural differences that are recognized in this stage may be perceived as either "new and exciting" or "threatening" (p. 141). In the second stage, disintegration, the person becomes aware of the significant differences between the home and host culture and experiences "bewilderment," "conflict," and "culture shock" (pp. 141-142). In reintegration, the third stage, the person attempts to come to grips with the difficulties in stage two. Often, stereotypes and judgemental attitudes emerge as a way of dealing with cultural differences and similarities. The person seems caught between two cultures. In the fourth stage, autonomy, "One's outlook becomes increasingly flexible. . . [and one] accepts and appreciates cultural similarities and differences." In the last stage, double-swing, the person is able to completely accept both similarities and differences in the host culture. "One is independent, yet simultaneously interdependent" (p. 142). At this stage, "one becomes capable of bringing new ways to explore the paradox of human diversity and unity" (p. 142).

Taft (1977) describes four processes a sojourner may experience in the host country. The first, cultural adjustment, occurs when the sojourner is comfortable in the host society. The second, identification, occurs when the person feels a sense of belonging in the host culture. The third, cultural competence, exists when the person is able to speak the local language well and is able to behave 
appropriately in a variety of contexts. Role acculturation occurs when the person perceives the host culture's attitudes and his to be the same. Taft points out that sojourners who are in the host country to complete a goal and plan to return to their home country do not need to achieve role acculturation in order to adjust well to the host society.

Although Yoshikawa's and Taft's guides to cross-cultural adaptation might be useful in labeling a stage or stages in which a person might reside at any given time, they do not suggest factors which may contribute to adaptation. Brislin (1981) and Kim (1985), however, suggest how and why some people adapt or acculturate more rapidly and completely than others.

According to research cited by Brislin (1981, p. 70), there are certain traits and skills which contribute to the sojourner's success in cross-cultural experiences. Traits include an ability to accept points of view different from one's own, a positive self-concept, empathy, respect and flexibility in relations with others, intelligence, task orientation, and receptivity to feedback in order to improve the sojourn. Skills contributing to success included knowledge of subject matter, language skills, communication skills, taking advantage of opportunities, and the ability to use these skills in order to gain significant knowledge of the culture and to complete the major goal guided by gained knowledge and empathy. 
Brislin (1981) writes about the significance of affiliation with both fellow nationals and host nationals in facilitating adjustment. He points out that initial adjustment can be facilitated, and frustration and stress can be relieved, through interaction with fellow nationals. By assisting in orienting the sojourner to the new culture, and in sharing a similar cultural background, the fellow nationals provide a bridge for the sojourner. However, if affiliation with fellow nationals is the main social experience throughout the sojourn, acculturation will likely lag behind a person who divides his time between members of the host culture and fellow nationals.

Another factor that determines adjustment is the person's motivation. For some, the major reason a person is in the host country is to complete a task; for this person, there is often little interest in learning about or participating in the host culture. For others, the major motivation is to learn about the host country, and participation in the host culture is eagerly sought. Cultural adjustment will proceed differently and at a different pace given variations in motivation. Length of time in the host country might be a factor in determining the degree of acculturation, but individual differences suggest some people will adjust very well after several months and others will not adjust after several years (see Brislin, 1981, p. 282). 
One of Brislin's concerns which is of particular interest in examining the adjustment of chinese students in the U.S. is adaptation in pluralistic societies:

Although inadequate evidence exists to be certain, the use of many coping styles and several long-term adjustment strategies may be easier, less stressful, and more effective in pluralistic societies. In contrast to a monistic society, where a single set of norms is enforced, pluralistic societies encourage or at least tolerate heterogeneity with respect to the values and customs of different groups. . . . There is more likely to be a match between what the sojourner brings and what some segment of the society values, and more tolerance for any set of strategies and styles which (s)he chooses to use. (pp. 288-289)

Kim (1985) suggests that communication is central

to acculturation. She likens the immigrant's accul-

turation process to that of a native-born person.

Both are acculturated through communication.

Much of the acculturation process is to adapt to, and adopt, predominant patterns and rules of communication of the host culture. The acquired host communication competence, in turn, facilitates all other aspects of adjustment in the host society. Communication, therefore, is viewed as the major underlying process as well as an outcome of the acculturation process. (Kim, 1985, p. 383)

Kim points out that acculturation patterns are not standardized; variations are often determined by an individual's acculturation potential. The acculturation potential is "determined by their preimmigration characteristics" ( $p$. 383). Kim lists some of the more important characteristics. Similar to some of Brislin's traits, Kim describes 
the importance of personality factors, "such as gregariousness, tolerance for ambiguity, risk-taking, cognitive flexibility, open-mindedness, and other related characteristics" which "are likely to help restructure the immigrant's perception, feelings, and behaviors" (p. 383). According to Kim, there are other important indicators of acculturation potential. "Education, regardless of its cultural context, appears to expand a person's capacity for new learning and the challenges of life" (p. 383). In addition, older persons often experience more difficulty adjusting to a new cultural environment. Also, familarity with the host culture may increase acculturation potential. Kim points out that the

similarity of the original culture to the host culture is perhaps one of the most important factors of acculturation potential. . . To the extent that we can understand the similarities and discrepancies between an immigrant's original cultural background and the host culture, we can better understand the immigrant's acculturation potential. (p 383)

If we accept Kim's assessment that the more discrepant the native and host cultures are, the less the potential for acculturation, where does that lead us in our search to understand the Chinese student's experience in the U.S.?

Cultural Characteristics: China and the U.S.

A sampling of literature on cultural characteristics suggests a number of differences between Chinese and Americans. American culture has been scrutinized and explicated 
by Perry (1949), Stewart (1972), Rapson (1967) and more recently by Bellah, Madsen, Sullivan, Swidler and Tipton (1986). Similarly, Chinese cultural patterns have been examined (Bond, 1986; Dernberger, Dewoskin, Goldstein, Murphey and Whyte, 1986; Marsella, DeVos, and Hsu, 1985; Munro 1985; and Nakamura, 1964). Additionally, some authors have focused their attention on comparative studies of culture in the U.S. and China (Barnouw, 1973; Hofstede, 1980; and Hsu, 1981, 1983). All of these works, regardless of their style or the other issues they address, highlight the disparate cultural patterns of China and the U.S. For example, in contrasting how time is perceived, Stewart (1972) points out that Americans see time as rushing to the future, and in that sense, it is closely associated with progress. Stewart links this notion of time to seeing the world in a causal scenario where events are explainable in terms of antecedent conditions. The chinese, however, do not share this concept of cause and effect.

The Chinese demonstrates a much greater situation-centeredness and seeks an explanation for a specific happening in terms of other factors occurring at the same time as the event in question. . . This view of time inclines the Chinese to integrate with the environment rather than master it, and to adapt to a situation rather than change it. (p. 67)

Nakamura (1964) observes that the Chinese give much attention to the particular rather than the universal. This preference is evidenced in explaining and teaching-- 
where particular, concrete, and intuitive explanations and examples are preferred to discussing general principles. Stewart contrasts Chinese and western styles of thinking:

The Chinese pattern of thinking provides an accentuated example of the relational style, and for this reason, from the Western point of view, it lacks clarity. The chinese do not analyze a topic divisively by breaking it down into parts. Their thinking is based upon concrete conception weighted with judgment and lacking the precision and abstraction of western concepts. (p. 25)

In Habits of the Heart: Individualism and commitment in American Life, Bellah, Madsen, Sullivan, Swidler, and Tipton (1986) cite Ralph Waldo Emerson in their description of the development of self-reliance in American society:

Society is everywhere in conspiracy against the manhood of every one of its members. . . Then again, do not tell me, as a good man did to-day of my obligation to put all poor men in good situations. Are they my poor? (p. 55)

The authors point out that although self-reliance is a nineteenth century term made popular by Emerson, selfreliance as a word and concept continues to come easily to the tongues of those Americans they interview. Dependence, on the opposite end of the continuum from self-reliance, is highly valued in chinese culture.

And among the Chinese, dependence on others is desirable for it strengthens the relationship among people. Chinese parents, for instance, take pride in being dependent on their children and supported by them in a manner to which they are unaccustomed. (Stewart, 1972, p. 72) 
Time, ways of thinking, self-reliance, and dependence are but a few of the areas where Chinese and American cultural differences are noted.

Factors which may Influence the cultural Adaptation of Chinese students in the U.S.

If Kim's assessment (i.e., that similarity of the host and original cultures may be one of the most important indicators of acculturation potential) is accurate, then this sampling of differing cultural characteristics in China and the U.S. does not bode well for chinese students in America. However, one factor grounded in recent historical changes in China does suggest a lessening of U.S.-China discrepancies. As orleans indicates:

Monetary gain rather than ideology has become the motivating force in China and, in the process, there has been a gradual transition during which national interest became subsumed by a strong sense of individual interest. (1988, p. 48)

If modifications in generally-accepted Chinese cultural characteristics have occurred, how might these changes influence the cultural adjustment of chinese students in the U.S.?

Brislin offers another factor that might work to lessen the problems of acculturation for chinese nationals coming to the U.S. It may be easier for a sojourner to adjust to a host culture that is pluralistic than one that is monistic. This would seem to suggest that adjustment 
for a chinese student in the U.S. is facilitated by the pluralistic nature of American society. Confounding this facilitation, however, is orleans's assessment that Chinese students are "pushed away" from china and retain loyalty to their homeland (see p. 3). This might suggest that their cultural adaptation in the U.S. could be difficult.

One useful heuristic for exploring cultural experience is Hall's (1976) concept of high- and low-context cultures. Hall characterizes a high-context culture as one in which "people are deeply involved with each other. . . information is widely shared" and "simple messages with deep meaning flow freely" (p. 91). He describes a low-context culture as "highly individualized," "somewhat alienated," with "relatively little involvement with people" (p. 91). Further, Hall points out that the meaning of a high-context message is embedded in the physical context, i.e., internalized within the person's knowledge of contextual factors which affect interpersonal interaction; very little is in the "coded, explicit, transmitted message" (p. 91). A lowcontext message, on the other hand, relies almost completely on the explicit code. Additionally, Hall suggests that the higher a culture is on the continuum of cultural contexts, the more aware its members will be of the selective screen between themselves and the outside world. According to Hall, China is at the high-context end of the scale and American culture is at the low-context end. 
In contrast to low-context communication, Hall describes high-context communication as "economical, fast, efficient, and satisfying" (p. 101). However, he points out that the message will be incomplete if time has not been devoted to the requisite cultural grounding. Further, he points out that high-context communications are "unifying," "cohesive," "long-lived," and "slow to change" (p. 101). Low-context communications do not unify and change rapidly and easily.

Several studies have pointed out notable differences between high-context cultures (HCC) and low-context cultures (LCC). In one study, Gudykunst (1983) found that members of HCC appear to be more cautious of strangers than LCC members. Also, HCC members made more assumptions about strangers based on strangers' cultural backgrounds and, similarly, used more background interrogation to reduce uncertainty. This seems to fit Hall's description of members of HCC having more awareness of the filter that culture provides. Gudykunst also found in this study that HCC members engaged in less nonverbal behavior during initial interactions.

Gudykunst and Nishida (1986) point out that:

It appears there are social behaviors or types of information that are more important sources of uncertainty in high-context cultures than in low-context cultures, including the following: (1) knowing others' social background, knowing whether others will behave in a socially appropriate manner, (3) knowing that others understand individuals' feelings, (4) knowing 
what others mean when they communicate, and (5) knowing whether others will make allowances for individuals when they communicate. (p. 529)

Additionally, Gudykunst and Nishida suggest that information gathered in a LCC regarding attitudes, values, emotions, and past behavior focuses on the individual. In a HCC, however, social information carries more weight. For example, a HCC inquirer is likely to be more interested in a person's institutional affiliation than in the specifics of the person's job.

A number of comparative studies have been done which focus on the HCC/LCC distinction. In one such study (Alexander, Cronen, Kang, Tsou, and Banks, 1986), relationship development was studied in Chinese and American students. The researchers found that chinese students classified more conversation topics as "prohibitive" whereas American students classified more topics as obligated.

okabe (1983) describes a HCC as one which places great confidence in non-verbal skills, while treating verbal skills as suspect. Okabe relates this emphasis on nonverbal communication to the values of interdependence and harmony which require words to be used implicitly and ambiguously.

Studies which Bear Upon the Adaptation of Chinese Students in the U.S.

In studying cross-cultural adaptation of Chinese students in the U.S., Yeh (1975) found that Chinese students 
spend most of their time with fellow nationals. They rarely establish warm or satisfying relationships with host nationals, and they "generally feel vulnerable and at high risk during much of their stay in the United states" ( $p$. 96). Students not only experience difficulty in adjusting to new "foods, climate, language, mannerisms and communication, [but] these students also suffer from status change and status loss" (p. 96). Yeh suggests that their primary interest is "to study," "to get a degree" (p. 97). Yeh characterizes the Chinese students' experience in the West as "a period of servitude to be endured. . . . a postponement of the moment when life can be enjoyed. Not infrequently they live in semipoverty and constant anxiety about studies" (p. 97) .

Yao (1983) points out some of the difficulties Chinese students experience in adapting to life in the U.S. Students do not develop (and even sometimes lose) their command of spoken English because they frequently spend most out-of-class time with fellow Chinese. Students' financial conditions are often desperate and, in seeking both financial and spiritual support, they tend to apply to universities with large Chinese communities. She points out that the differences between Chinese and American values "regarding sex, marriage, filial piety, and family responsibilities. . . generate various degrees of cultural conflicts" (p. 40). 
The Yeh and Yao studies were based on Chinese (from Taiwan, Hong Kong, and other Asian countries) who were studying in the U.S. Neither work identifies how data were gathered. META-THEORETICAL ISSUES IN THE STUDY OF CULTURAL
EXPERIENCE AND ADAPTATION

\section{World View I and World View II}

Hall's (1976) concept of high- and low-context cultures is born out of years of observational data collection. It is not, however, grounded in a particular world view for theory generation. In this sense, it could be considered pre-theoretic and, therefore, potentially amenable to use within research studies based in either a World View I or World View II perspective.

Littlejohn (1983) directs our attention to the differences between World Views I and II. World View I "treats reality as distinct from the human being, something that people discover outside themselves. It assumes a physical, knowable reality that is self-evident to the trained observer" (p. 20). According to Littlejohn, communication theory and research in WV I is characterized by behavioristic methods, strict operations, a search for covering laws and universal statements, reductionism, and viewing the human being as a reactive object whose behavior becomes explainable in terms of antecedent conditions of the environment. 
By contrast:

World View II attempts not to uncover universal laws but to describe the rich context in which individuals operate. It is humanistic in that it stresses the individual subjective response. Knowing is interpreting, an activity everybody is believed to engage in. (Littlejohn, 1983, p. 21).

Littlejohn (1983) points out qualities that characterize WV II: interpretation by the researcher takes precedence over objective observation; tacit processes are uncovered; an emphasis on social knowledge through symbolic interaction; an emphasis on human differences, and a focus on the process of communication.

Proceeding from WV I assumptions, Gudykunst (1983, 1986) has effectively used Hall's concept of high- and low-context cultures in causally-based research. In his work, he attempts to predict the influence of antecedents (HCC/LCC) upon consequents (e.g., important information to gather), and to discover culturally-distinct regularities in those causal relationships.

As mentioned earlier, Hall's concept of high- and lowcontext culture is pre-theoretic. Therefore, it can be appropriated for use in research taking a WV II position, beginning with the assumption that "communication itself is a vital vehicle in the social construction of reality" (Littlejohn, 1983, p. 21). Humans act intentionally, and it is through the activity of communication that social knowledge is acquired and the shape of social reality 
emerges; these assumptions collectively constitute the "action" tradition.

The Action Tradition and the Role of Normative Force

Cushman (1977) describes how analytic philosophers in the action tradition (specifically, G. H. von wright and T. Mischel) view human beings as having power to act. Human actions are prompted by actors' intentions. Actors are inclined to follow rule-governed patterns of behavior, and the patterns become the regularities

linking the intention to the behavior. such an explanation of human behavior is viewed as teleological. . . Teleological behaviors have two parts. The first consists of an inner part or intention rooted in previous experience. The second consists of an outer part which has two aspects: a muscular activity, interfering with a cause in nature, and the consequences which ensue from that interference (Cushman, 1977, p. 35).

Additionally the rule-governed patterns of behavior are assumed to carry normative force. Cushman and Pearce (1977), drawing from von wright (1971), suggest that:

Normative forces exert pressure on actors to select certain goals and the appropriate means for achieving the specified goal. Normative pressures may be exerted on an actor by a culture, an organization, a group, or by the actor's own set of values. The force of practical necessity rests on the power of an actor to respond to normative pressures in selecting goals and the means for achieving them. . . . Practical necessity depends on the type and amount of normative force an actor feels to perform (or not perform) a given activity in a specified way. (p. 345) 
Both the teleological nature of human action and the normative force of rules for pursuing goals in sociallysanctioned ways find their expression in the practical syllogism:

A seeks B. In order to accomplish B, A must do $r, s, t, u, v$. and so on. A sets out to do $r$, $s, t, u, v$ (in appropriate ways).

Unlike the logical syllogism, no conclusion or outcome (the attainment of " $\mathrm{B}$ ") is specified. It simply notes the intentional nature of human action and those activities that the action sees as instrumental in reaching the desired goal. Moreover, the syllogism assumes that these activities are arbitrary and socially negotiated--that is, their enactment is rule-governed.

Both ideas--behavior as intentional, "rooted in previous experience" (Cushman, 1977, p. 35) and normative force --hold significant implications for Hall's (1976) concept of high- and low-context cultures. Both suggest the influence of previous experience (i.e., culturally-grounded experience) on actors' behaviors and interpretations. As Pilotta (1983) observes,

- .all phenomena, from natural to supernatural, play a role and are comprehensible within a cultural matrix which establishes for these phenomena their characteristic locus, significance, import, and stress (p. 273, emphasis added)

We would, therefore, expect that HCC actors and LCC actors are subject to distinctly different constellations 
of normative forces. These internalized cultural constraints are manifested in actors' selection of different goals and different means for achieving them. Normative force to act or not act, and to act in certain prescribed ways but not in others, is culturally based. Potentially, this creates a dilemma for a person who has been reared in a culture that is at one end of the context continuum and yet lives--and consequently communicates--in a culture at the other end. Specifically, how does this person find interaction meaningful when the usual contextual constraints of the primary cultural orientation are removed? Additionally, how does adaptation to an alternate set of rules for action and interpretation proceed over the course of one's stay in the host country?

\section{Rules: The Basis for Action and Interpretation}

Berger and Luckmann (1967) point out that "reality is socially constructed" and the task of research in the action tradition, which they label "the sociology of knowledge," is to analyze the processes in which this occurs" (p. 1). Berger and Luckmann also stress that although there are different definitions of the nature and scope of actional inquiry, there is agreement that it is concerned with the relationship between human thought and the social context within which it arises (p. 4). Additionally, they address the need for a more extensive focus on "commonsense knowledge": 
The theoretical formulations of reality, whether they be scientific or philosophical or even mythological, do not exhaust what is 'real' for the members of a society. In other words, commonsense 'knowledge' rather than 'ideas' must be the central focus for the sociology of knowledge. It is precisely this 'knowledge' that constitutes the fabric of meanings without which no society could exist. The sociology of knowledge, therefore, must concern itself with the social construction of reality. (p. 15)

As we move the study of culture from the dominant WV I perspective to that of WV II, we find the following: culture ceases to be an objective, observable phenomenon in the natural world; it transforms into the phenomenal experience of the lived world by the actor.

Each culture, through the normative force of rules, directs in a unique way the social construction of reality. From this perspective, rules are used in each culture to coordinate communication and interpret experience. As Shimanoff (1980) observes:

- . in order for communication to exist, or continue, two or more interacting individuals must share rules for using symbols. Not only must they have rules for individual symbols, but they must also agree on such matters as how to take turns at speaking, how to be polite, how to insult, to greet and so forth. If every symbol user manipulated symbols at random, the result would be chaos rather than communication. (pp. 31-32)

As previously noted, the action principle states that the most significant behaviors of individuals are initiated by the individual as opposed to the motion principle which sees behavior as determined by prior cause. Another 
premise is that social behavior is organized, structured, and at the same time highly contextual. It is through rules that social action is organized. Interaction structure can be understood in terms of the rules that govern it; rules influence the options available in a given situation and rules are contextual (Littlejohn, 1983). Cushman (1977), drawing from Mischel, points out that, "Neither experience nor thought can be understood as things that happen to us, but only as things we do in accordance with rules" (p. 35).

Rules theory carries numerous implications for Hall's concept of high- and low-context cultures. Rules organize action, influence options available in a given context, coordinate communication, and assist in interpreting experience and understanding interaction structure. In addition, the normative force of a rule is significantly influenced by culture. As Gudykunst's (1983) and Alexander et al.'s (1986) studies suggest, there are different rules for initial meetings and relationship development in low- and high-context cultures. In a high-context culture, like China, interactants" "choices are informed extensively by contextual cues and by shared presuppositions of the culture" (Ehrenhaus, 1983, p. 267). Moreover,

Each cultural tradition offers us a unique way of 'being human' and thus unique ways of perceiving our world and ourselves. But to appreciate other ways of experiencing the human condition we must step into the frightening unknown--where the rules for making sense and 
achieving coordinated action are unilluminated. (Alexander, et al., 1986, p. 66)

Rules theorists have assigned a variety of meanings to the concept of rule. However, for the purposes of this study, shimanoff's (1980) integrative work in rules theory has been enlisted. To bring light to those rules for coordinating communication and interpreting experience, shimanoff identifies four ways of viewing the normative force of rules: obligation (an action one should take in order to act appropriately in a situation), prohibition (an action one should not take in order to act appropriately in a situation), permission (an action which is not influenced by either obligation or prohibition--free choice) and preference (among a number of possible choices, some actions are more desirable). I have used these four ways of understanding normative force to guide systematic inquiry into actors' interpretations of intercultural interactions. (See Chapter III).

\section{GENERAL RESEARCH QUESTIONS}

This study examines how Chinese students and scholars from the People's Republic of China (a high-context culture) interpret interactions with Americans in the low-context culture of the United States and how these interpretations change over the course of their stays in the U.S. The research will be limited in scale and focus--in terms 
of the number of respondents, the geographical area from which they are drawn, and the focus of the interview questions (see Interview Schedule, Appendix B). The details of these parameters are further described in Methods, Chapter III.

The research questions are guided by the assumption that actors' interpretations are influenced by the rules of their native culture.

In view of the normative force of rules learned in a high-context culture, how do chinese interpret interactions with Americans within the lowcontext culture of the U.S.?

Further, how do these interpretations change over the course of their tenure in the U.S.?

More specifically, shimanoff's four types of normative force of rules (prohibited, obligated, permitted, preferred) are used to structure lines of investigation in depth interviewing.

SPECIFIC RESEARCH QUESTIONS

In applying Shimanoff's four ways of understanding normative force to the general research questions the following specific research questions were developed.

1. When Chinese encounter situations in which they would expect obligatory normative force to be in effect, but find it is not, how do they interpret these encounters and how have these interpretations changed over their tenure in the U.S.?

2. When chinese encounter situations in which they would expect prohibited normative force to be in effect, but find it is not, how do they interpret these encounters and how have these interpretations changed over their tenure in the U.S.? 
3. When Chinese encounter situations in which they would expect a wide range of acceptable (i.e., high permissibility and preferability) normative force to be in effect, but find it is not, how do they interpret these encounters and how have these interpretations changed over their tenure in the U.S.?

4. When Chinese encounter situations in which they would expect obligatory normative force to be in effect, and find it is, how do they interpret these encounters and how have these interpretations changed over their tenure in the U.S.?

5. When Chinese encounter situations they would expect prohibited normative force to be in effect, and find it is, how do they interpret these encounters and how have these interpretations changed over their tenure in the U.S.?

6. When Chinese encounter situations in which they expect a wide range of acceptable (i.e., high permissibility and preferability) normative force to be in effect, and find it is, how do they interpret these encounters and how have these interpretations changed over their tenure in the U.S.?

This study will collect data through intensive interviewing of actors in a field setting. The study's purpose is not to gather, describe and organize "sets of rules" that Chinese students rely on. Rather, the focus is on how, through rules, Chinese make sense of their encounters with Americans (in interpersonal interaction) and with American cultural practices. This focus places the study squarely within the concerns of phenomenology. Casmir (1983) stresses that

- .phenomenology can be most useful in exploring concerns about the nature of self-experience, values, and human relationships where \{traditional\} science alone cannot give the fundamental responses to these particularly human concerns. (p. 313) 
Chapter III details the methods and procedures used in this study. Additionally, assumptions with which this inquiry proceeds are further stated in Chapter III. 
CHAPTER III

METHODOLOGY

\section{PHENOMENOLOGY AS A FRAMEWORK}

This study is guided by a philosophical framework of phenomenology. There are a variety of definitions that scholars ascribe to phenomenology. However, many of these definitions have their roots in the extensive writings of Husserl and Heidegger. These philosophers differ somewhat in their conception of what phenomenology has to offer. Husserl believed truth could be discovered through systematic elimination of subjective factors which cloud pure experience; Heidegger disagreed, teaching that it is impossible for humans to eliminate their subjective experience. He believed that ". . . what is most important in human life is the natural experience of merely being in the world" (Littlejohn, 1989, p. 137). However, both share a general set of assumptions that distinguish phenomenology as a philosophical approach. The focus in phenomenological study is the consciously-lived experience of human beings from their own perspective and the significance of language and interaction as vehicles through which meanings arise. 
Taylor and Bogdan draw from Max Weber (1968) in observing that the phenomenologist seeks verstehen, "understanding on a personal level the motives and beliefs behind people's actions" (p. 2). Palmer (1969) points out that "phenomenology means letting things become manifest as they are, without forcing our own categories on them" (p. 128).

Casmir (1983, p. 311) stresses that contemporary phenomenology "emphasizes intentional consciousness which allows whatever meaning there is in a communicative event to emerge between individuals in such communication." Similarly, Hawes (1977, p. 3) defines phenomenology as "the study of being as it manifests itself in and through language use." Both researchers recommend direct encounter with events.

Taylor and Bogdan (1984) emphasize that The phenomenologist is committed to understanding social phenomena from the actor's own perspective. . . The important reality is what people perceive it to be. (p. 2)

\section{QUALITATIVE RESEARCH METHODS}

Because phenomenological inquiry focuses on understanding from the actor's perspective, methods of inquiry must focus on gaining access to that perspective. These methods are generally qualitative and usually include participant observation or in-depth interviewing.

Taylor and Bogdan (1984) cite ten characteristics of qualitative methodology: 1 . It is inductive. Theory is 
developed from the data. Data is not collected to test "preconceived models." 2. Researchers view people and settings as wholes, not as a mass of variables. 3. Researchers "interact with informants in a natural and unobtrusive manner." 4. Researchers empathize with those they study. 5. The researcher sees events "as though they were happening for the first time." 6. ". . all perspectives are valuable." 7. Informants are treated as complex human beings worthy of individual study. 8. Validity is emphasized: "first-hand knowledge of social life unfiltered through concepts, operational definitions, and rating scales." 9. ". . . all settings and people are worthy of study." 10. "Qualitative research is a craft." Both researcher and method must be flexible. "There are guidelines to be followed, but never rules. The methods serve the researcher; never is the researcher a slave to procedure and technique." (pp. 5-8) Taylor and Bogdan's characteristics have been accepted as basic assumptions in this study.

As Bogdan and Taylor point out, research using qualitative methods must necessarily proceed in a flexible way to "capture" the respondents' "process of interpretation." (p. 9) It is not possible to firmly establish at the outset exactly how research will proceed. In this sense, qualitative methods can be considered non-linear, following no one pre-ordered sequencing of procedures. In distinct 
contrast is the linear nature of "the scientific method" wherein it is essential that research is carefully planned and adhered to in the search for cause, prediction, and verification. According to Philipsen (1977):

The requirements of naturalistic inquiry can make it difficult to design and conduct research according to the standards of linearity which are implicitly or explicitly reflected in scientific inquiry in speech communication. (p. 42)

Glaser and Strauss (1967) argue against a preoccupation with verification of theory and the "resultant deemphasis on the prior step of discovering what concepts and hypotheses are relevant for the area that one wishes to research" (1967, p. 2). Rather, they argue for an inductive approach to theory generation based upon the systematic study of particular social phenomena. Through detailed observation and participation with the social phenomenon/ context it becomes possible to develop an explanatory system for that phenomenon. Only later, through comparative analysis, does generalization become a theoretical concern.

In keeping with Glaser and Strauss's approach to theory-building, the purpose of this study is not to verify existing theory. Rather, it is to discover how a sample of Chinese students and scholars interpret their interactions in the U.S. and to generate theory from these data. Glaser and strauss (1967) refer to the generation of theory from data as grounded theory. Consistent with efforts designed 
to generate grounded theory, I have attempted to collect detailed data--data essential to "thick description" (Geertz, 1973, pp. 3-30). Consequently as data have been gathered, it has been essential to be flexible--both in the way in which data have been collected and the areas of inquiry which are further probed. For instance, prominent and prevalent issues, contexts, and categories have arisen from the data. These have often changed and been refined as data continued to be collected. Quite reasonably, these have necessitated questioning beyond the "formal" Interview Schedule.

\section{RESPONDENTS}

Twenty-four respondents were interviewed. Respondents were students and scholars from the People's Republic of China who were teaching and/or studying at nine colleges and universities in Western oregon during the fall and winter of 1988-89. The interviewer contacted the international student offices at most of these colleges or universities and asked the advisor if there were students or scholars who might be interested in being interviewed. In most cases, the interviewer sent a letter describing the study to potential interviewees suggested by the advisors (Appendix A). Enclosed with the letters were postcards that students and scholars were asked to return if they were interested in participating. At two schools, the 
name and telephone number of the President of the chinese Student Association was given as a source for students. At one school this worked very effectively, with more students interested than could be interviewed. At the other, it was very difficult to contact the President by phone, and a letter and postcard received no response. other than this one school, there was no difficulty in finding students and scholars who were interested in being interviewed. Twelve students and scholars were suggested by advisors. All returned the postcards and twelve were interviewed.

Additionally, the technique of snowball sampling (Coleman, 1958) was used in this study. Much as its name portrays, one respondent is chosen, and that person volunteers information about other persons, which in turn leads to interviews with those persons. The "second generation" of respondents leads to the third. This technique was particularly appropriate to the present study because it was impossible to know beforehand what salient issues would emerge during the interviews or who would necessarily be a valuable source of information. With the snowball method, it was possible to follow up on emerging issues by choosing respondents who were able to speak to them.

Within the total sample of twenty four, sixteen respondents were males, eight were females. The youngest respondent was twenty one; the oldest was fifty one. Fifteen 
members of the sample were in their twenties. Six were in their thirties, and three were forty or older. The shortest time in the U.S. for a respondent was four months; the longest time was five years. Approximately one third of the sample had been here for four to five months. The average time in the U.S. for the remainder of the group was approximately two years. Nine respondents had never lived with Americans. The rest had lived with Americans for as short a time as three months to as long as four years. Four respondents were previously known to the interviewer.

\section{THE INTERVIEW SCHEDULE}

As was noted in Chapter II, the conceptual framework used to develop the Interview Schedule (see Appendix B) was based on the work of Shimanoff (1980). The planned primary questions in the Interview Schedule address respondents' interpretations and behaviors in terms of four types of normative force: obligatory, prohibited, preferred, and permissible courses of action in specified social situations.

Intensive interviews that were "moderately scheduled" were used to collect data. Moderately scheduled interviews contain open-ended questions and offer freedom to probe and adjust to different interviewees and situations (stewart and Cash, 1988) 
The primary questions on the Interview schedule focus on obligation, prohibition, preference, and permission as a way of understanding how, through rules, chinese interpret interaction in the U.S. However, the questions were also designed to be general and open-ended in order to encourage respondents to talk about issues that were most important to them. Additionally, respondents were queried as to how their behaviors and interpretations have changed over their tenure in the U.S. Categories for probing are listed at the end of the Interview schedule. They were used as more specific areas of inquiry if respondents had difficulty answering a general question. The Interview Schedule was treated as a flexible tool of inquiry within which it was possible to rearrange areas of questioning to fit the interviewee. Additional areas of questioning were pursued as issues of importance to respondents arose, as the interviewer wanted to understand the thinking behind a belief or action, or as categories and contexts arose which seemed to be significant to the previously collected data.

In a pre-test of five respondents, questions from the Interview schedule were answered readily and with much detail by three people. One person answered most of the questions readily and generously; however, she did not have a response for several questions despite being asked about specific topics. One person answered most of the questions --although rarely in great detail--and suggested it would 
probably be better "just to talk with people instead of asking these questions."

The pre-test was useful in informing the interviewer of several limitations in the Interview Schedule. The intention was that the first questions (in the areas of obligation, prohibition, and permissibility/preferability) would focus on early experiences in the U.S. so it would be possible to contrast these responses with responses to later questions related to change. It was difficult for some respondents to remember their early experiences. Therefore, it seemed as though it might be useful to begin the interview by talking informally about "what it was like when you first arrived in the U.S. What were the first few days and months like"? Throughout the interviews, this proved very effective. First, it seemed to relax people; it was something they wanted to talk about. Second, it seemed to help people "take themselves back" to those early experiences in the U.S.

In general, questions were frequently rephrased in an effort to make them clear to each participant. often times, restatements were determined by 1) experience with previous respondents, or 2) interaction with the respondent being interviewed (in terms of language use, areas of interest, phrases used, etc.) In coming to terms with several respondents' beliefs that we should simply talk, I decided that if a respondent seemed uncomfortable with the 
interview questions, I would encourage a less structured dialogue. Within this dialogue, I looked for opportunities to probe the areas of obligation, prohibition, and permission/preferability as well as the respondents' changing expectations.

Lofland and Lofland (1984) point out the importance of flexibility in the Interview Schedule.

...a [interview] guide is not a tightly structured set of questions to be asked verbatim as written, accompanied by an associated range of preworded answers.... You want interviewees to speak freely in their own terms about a set of concerns you bring to the interaction, plus whatever else they might introduce. (p. 59)

The Interview Schedule was effective in gathering data from approximately two-thirds of the respondents (16). It was most effective with respondents who had a strong grasp of English. In most cases these were respondents who had been in the U.S. at least a year. However, several respondents who had been here only a few months followed each interview question with richly detailed responses, while several respondents who had been here longer than a year seemed to have difficulty understanding the questions.

Several respondents stated that they did not enjoy answering the questions; they felt "just talking" was better. With these respondents I abandoned the Interview Schedule and asked very broad, general questions such as: What is life like for you here in the U.S.? What are the events that stand out to you during your time here? What 
was it like when you were first here? What do you find here that you like a lot? What do you find that you do not like? What stands out to you about the way Americans treat one another, or treat you? These interviews seemed to confirm the importance rules play in adaptation in that rules were not directly addressed, but issues bearing upon the obligation, prohibition, permission and preferability of actions were liberally sprinkled throughout the interviews--even without the use of the Interview Schedule.

When there was time, I also asked two additional questions after respondents had finished responding to the questions in the Interview schedule. First, I asked if there were events or issues that we had not talked about that the respondent felt were important to his or her experience in the U.S. Secondly, I asked what the respondent would tell a chinese student or scholar who was newly here or who was planning on coming to the U.S. which would be important to facilitate that person's adjustment.

One interview was a group interview which included five respondents. The interview was initially arranged with one respondent. When I phoned this respondent (who had returned a postcard expressing his interest in being interviewed), we had great difficulty understanding each other. We spent a long time on the telephone, and, finally, we arranged to meet. When we met, he was with two other chinese nationals. One was a young man and the other 
gentleman was middle-aged, like himself. The young man was more comfortable with English than the two older gentlemen, but still quite reticent. I later discovered each of them had been in the U.S. less than four months. The respondent, particularly, seemed bewildered by my interest in interviewing him. The young companion helped him translate his questions from Chinese to English. Because of the respondents' minimal grasp of spoken English and confusion (perhaps, mistrust), I did not feel I should use the Interview Schedule. I felt the questions on the Interview Schedule would exceed their understanding of English. Therefore, using them would be very insensitive to the respondents and would not be productive in gathering detailed data. Initially, I asked questions that I felt would be fairly easy to understand and would express my interest in and concern for them. The first questions I asked were informational: Where are you from in China? Why did you choose this school to visit? How long are you here for? Then I asked more personal questions: What has it been like for you here? Are there things that are surprising to you in the U.S.? As the three respondents seemed to be feeling more comfortable with me (the youngest respondent was doing most of the talking, but he was doing a lot of translating for the older gentlemen, who now seemed more comfortable communicating with me), another Chinese student joined us, and shortly, a Chinese scholar 
joined our group. These last two respondents had been in the U.S. less than four months also, but their command of English was much better than the first three respondents. Within half an hour, the group was actively talking with me and one another. At this point, I further probed the topics that emerged in our conversation.

In general, the Interview Schedule was quite successful whenever it was used. Additionally, the Interview Schedule was very effective in exploring the respondents' interpretations of rules. Through this exploration it has been possible to gain an understanding of how respondents make sense of situations where two rule systems collide. Even more significantly, this line of inquiry has created an opportunity to understand how respondents, through the choices they make, create new rules for social action-rules which are forged at the intersection of two divergent cultural systems. Details of respondents' interpretations and choices are given in chapter IV.

\section{PROCEDURES}

\section{Preliminary Information Given to Respondents}

The following information was given to respondents prior to the initial interview--often in a telephone contact. I introduced myself and said I was a graduate student writing a thesis about Chinese students and scholars in the U.S. Additionally, I explained to respondents that 
most interviews seemed to be about one and one half to two hours long, but some were shorter, others were longer. At the beginning of the interview, I reviewed that I was writing a thesis. I explained that my interest focused on how Chinese students and scholars come to understand interpersonal interaction in the United States--how people relate to one another here, how Americans treat one another, how they treat you. I would ask some questions about their early experiences in the U.S. After that, there would be questions about changes which have occurred in the way the respondent thinks about those particular experiences now. Further, I explained that there were no right or wrong answers. Also, it was pointed out that "I am most interested in your opinions and personal experiences." Respondents were encouraged to feel free to stop me at any time--if they did not understand my questioning, if they thought a particular topic was important to probe with other respondents, if they wished to return to a previous topic, or for any other reason.

I explained that all information that was given to me was confidential. "Anything you tell me is private. When I speak about this research or write about it, your name, your school, your home city, or other identifying information will not be included." I explained that tape recording the interviews is very helpful to me, and pointed out that I would be the only person to listen to the tapes. 
The respondent was then asked if he or she was comfortable with my recording our conversation.

The Informed Consent Form (see Appendix C) was then presented, and I explained that this has been used over the last several decades to protect people who participate in research. I asked them to please read it, and if they were comfortable with what it said, to please sign. I told them I would be happy to explain anything about the form which they did not understand. Some students seemed bewildered by the formality of such a form, and several commented that there was nothing like this in China and they were not worried about confidentiality. Finally, I explained that I would like to ask them a few quick questions before we started the interview. These questions were demographic. From their answers, the Face Sheet (see Appendix D) was filled out. After the completion of the Face sheet, the interview began in earnest.

\section{The Interview}

Interviews were conducted during the fall and winter of 1988-89. The length of interview varied from one and one half hours to four hours. All interviews were with a single person, except one group interview which included five respondents. For three respondents, interviews were held over three sessions, at weekly intervals. Interviews were conducted in offices, empty classrooms, apartments, 
conference rooms, student centers, dorm rooms, and, in one case, at the interviewer's home.

After several interviews I learned that it was not a good idea for me to interview a respondent after $8 \mathrm{pm}$. Both the respondent and I were too tired to expend the kind of energy the interviews seemed to require. Also, as an interviewer, I could not successfully handle more than two interviews in a day. For additional information on the interview, see The Interview Schedule beginning on page 36 of this chapter.

\section{Recording Data}

The intent was to tape record all interviews. However, in several interviews, problems were encountered which prevented the recording of parts or all of the interview. The tape recorder malfunctioned during one entire interview. However, since I was aware of the malfunction, interview notes were taken. The record button was not pressed down for part of another interview and that part of the interview was lost. The batteries had lost power during much of another interview. A second session was scheduled for this respondent. The group interview which included five respondents was not tape recorded since respondents were wary of the interviewer. Because of a very limited grasp of English, they had difficulty understanding and communicating with me. They appeared very 
concerned with my motivation for interviewing them (they asked what I wanted to know about them and why I was interested in chinese students and scholars several times) and did not seem to understand why I wished to talk with them. Consequently, I chose not to use the tape recorder in this situation.

\section{Transcription}

Interview tapes were transcribed within several days after each interview. Some tapes were very time consuming to transcribe either because of the interview length or because there was much distracting background noise on the tape which made it difficult to understand responses. The transcribed tapes do not contain the names of the respondent (or other identifying information) and have been given the same identifying number as the corresponding face sheet. A master list of respondent names with corresponding numbers is on file.

Field notes were written as soon as possible--usually, immediately after the interview. They include observations, interpretations, reactions to the interview, and recommendations for subsequent interviews. Time was scheduled time after each interview to review the interview and write field notes. However, I found myself in a situation two times in which the first interview of the day lasted so long, it was necessary to move into the second interview 
without time to write notes from the first. Also, two interviews continued until very late at night, and although I mentally reviewed the interviews while driving home, notes were not written until the next day. When interviews were not taped, notes were taken during the interview. However, I found it to be far preferable to tape the interview so it was possible to give full attention to the respondent during the interview. Therefore, whenever possible, interviews were taped. Both field notes and interview notes were copied and divided into relevant categories in much the same way as interview transcripts.

\section{Data Analysis}

Analysis occurred throughout data collection. In reflecting on and writing field notes after each interview, in listening to and re-thinking the taped interview, in reflecting on the interview as it was transcribed, in modifying the way questions were phrased based on information received in earlier interviews, and in making notes on issues and patterns, analysis was continually in process. Taylor and Bogdan (1984) discuss the relationship of data collection and on-going analysis:

Data collection and analysis go hand-in-hand. Throughout participant observation, in-depth interviewing, and other qualitative research, researchers keep track of emerging themes, read through their field notes or transcripts, and develop concepts and propositions to begin to make sense out of their data. (p. 128) 
Lofland and Lofland (1984) contrast research which focuses on a combined approach to data collection and analysis with an approach which divides data collection into one phase and analysis into another. They describe the former as being more productive, one in which:

- . analysis and data collection run concurrently for most of the time expended on the project, and the final stage of analysis (after data collection has ceased) becomes a period for bringing final order to previously developed ideas. Contrast this with the former situation, wherein the researcher, after data collection has ceased, has to begin to make some kind of coherent sense out of the mass of running descriptions, documents, and so on. (p. 131)

After transcribing each interview, an additional copy was made. The original has been kept in a master interview file. Each interview was carefully reviewed by the interviewer, looking for patterns, contexts, sayings, topic areas, metaphors and anything else that seemed notable in that particular interview.

A listing of each interview's significant topics was compiled (e.g., teacher/student relationships, interpretations, etc.) Interviews were read and re-read many times. The data seemed "almost memorized" at this point. Taylor and Bogdan (1984) point out that "you should know your data inside out" before intensive analysis begins, that you should "keep track of themes, hunches, interpretations and ideas," and that you should "look for emerging themes" (pp. $130-131)$ 
At this point, coding categories were developed. Index cards were prepared for each of the 43 emergent categories. Cards were then laid out on a desk and they were examined for the possibility of collapsing several categories. The cards were a very effective way of looking at the possible union of categories because it was easy to simply move cards around and "try them out" in different categories. As the categories became clearer (and fewer), the transcription was again carefully scrutinized many times for the presence of new categories or simply new ways of looking at the data. Taylor and Bogdan (1984) cite five steps in the coding process: "1. Develop coding categories. 2. Code all the data. 3. Sort the data into the coding categories. 4. See what data are left out. 5. Refine your analysis." (p. 138).

The second copy of the individual transcripts was then examined for "chunks" of data related to particular areas. These "chunks" were then identified by the respondent's number and a subject coding category and cut into pieces. Each piece was put into a pile that included pieces from other interviews where this subject was addressed. After this was accomplished, the piles were then reexamined for reconsideration of the subject area. Most pieces of data were included in one or more categories. However, a few pieces were set aside because they simply did not seem to fit into existing categories or warrant creation of new 
categories. Next, all of the pieces related to a particular subject area were stapled onto a piece of paper titled with that subject name. These subject groups were examined and reexamined for subject partnerships, patterns, emerging themes, metaphors, contexts, sayings--for those areas which were prominent because they arose frequently or because they arose powerfully for the respondents.

As I worked with the data, certain pieces shared a similar theme and seemed to repeat and weave together to form a "picture" which became more focused as my intimacy with the data increased. Certain phrases that respondents used stood out as though highlighted. A number of categories that initially captured my attention remain as important parts of the final analysis, however, a few waned in significance over the course of review and re-review. Bogdan and Taylor (1984) suggest: "By studying themes, constructing typologies, and relating different pieces of data to each other, the researcher gradually comes up with generalizations" (p. 134).

The following chapter presents and analyzes the interview data collected in this study. 
CHAPTER IV

DESCRIPTION/ANALYSIS

\section{INTRODUCTION}

Chapter IV highlights and analyzes data collected in this study. Description and analysis are divided into four major sections. These four sections reflect the developmental nature of this analysis. The first, orientations, describes groupings of respondents as perceived by the interviewer and respondents. The second, and largest section, Topics/Issues, consists of a number of subsections which became prominent as data were analyzed. They include Perceptions of America and Americans, Relationships, Critical Incidents/Critical Issues, Adaptation, The Impenetrable, A Chance of a Lifetime, and Respondents' Advice to Chinese. Description is emphasized throughout these subsections. The third and fourth sections, Patterns: Prohibited, obligated, Permitted and Preferred Actions and Patterns of Reasoning and Action: Chinese Students' and Scholars' Intercultural Experience, bring the data and analysis in the Topics/Issues section into perspective as broad patterns are examined. The emphasis in these final sections is on analysis. 


\section{ORIENTATIONS}

Respondents roughly fell into three orientations. One group could be categorized as eager to adapt. Another could be thought of as tolerating U.S. customs in order to accomplish a goal, and a third could be categorized as wait and see. Members of this last group seemed neither to be avid participants in U.S. culture nor avid advocates of their home culture's values and practices.

The eager to adapt group is characterized by a receptivity to U.S. culture. A 21 year old male who has been here about a year and a half articulates this pliancy: "When I first came here, my mind was not full. I'm still learning and changing." This group finds pleasure in being identified with Americans. A 25 year old female who has been here two and a half years reports: "I think I speak out more than the other oriental people in class. If I don't understand, I ask questions. I do a lot, like Americans." A 27 year old male who has been here about three years states: "Lots of people, if I talk with them, think I'm a native American." While members of the other groups experience change in their thinking and behavior during the time they are in the U.S., this group not only experiences change but finds change not merely practical but inherently desirable. A 29 year old female who has been here about two years states, "I feel that Americans work very hard and I prefer to, too. If you do not want to 
work and get everything, it is not good." A 24 year old male who has been in the U.S. nine months reports: "Sometimes I like to act like Americans--they are very openminded, they are very honest; they like to talk their own ideas. . . I like the way of straightforward." This group includes approximately one third of the respondents, male and female, aged 21 through 34 who have been in the U.S. from less than a year to just less than three years. The second group, which I have described as tolerating U.S customs in order to accomplish a goal, finds certain ways of thinking and acting in the U.S. unacceptable. This is not to say that members of this group find nothing acceptable or even preferable about life in the U.S., but those areas which they find unacceptable are very significant to their view of what life should or should not hold. A 39 year old respondent, in the U.S. for two years, talks about some of the things that are unacceptable to her:

There are some things in this culture I still can't stand--too much sex, talk about it, and divorce. Parents pay their children to do work at their house. I can't understand this. It is your duty to care for your brothers and sisters.

A 36 year old respondent who has been here five years talks about his observations of and experiences with relationships in the U.S.: "They [Americans] do not act the way I think they should. If you need something, you have to say 'I really need it,' otherwise they won't 
eare." When a 50 year old respondent, who has been in the U.S. about four months, was asked what he found surprising about the way Americans treated one another, he replied:

competition--too much competition. The older men retire. They are not so rich, so I think they feel lonesome. The young men--their ability, their energy; they occupy important positions but they do not take care of the older parent. . . In China, it is the children's duty to care for their parents. There, parents take very good care of their children. When parents are older, of course the children must take very good care of them. . . . I think for a society the family is the element. If family is happy, harmonious, then the whole society can be something like a good neighbor.

When a 26 year old respondent who has been in the U.S. three years was asked in what ways she has changed, she stated :

When I first came, I think I was more intimidated, so I just looked how they [Americans] acted, and that's the way they did things without any more judgement. Now I think that's weird the way they do that.

This group includes approximately one fourth of the respondents, male and female, aged 26 through 50 who have been in the U.S. from four months to five years.

The wait and see group was the most circumspect of the three orientations. Their responses expressed a less powerful commitment either to U.S. customs or to the "rightness" of particular interactional practices in China. They did, however, observe and comment on differences and were curious about U.S. cultural practices. This group comprised more than one third of the respondents, male and female, 
aged 21 through 50, who have been in the U.S. from four months to nine months. It is important to point out that most members of this group have been in the U.S. a brief period of time--less than six months. Therefore, it would not be surprising if many felt their impressions were too limited or tentative to make commitments to positions. Or, perhaps, some were uncomfortable verbalizing their positions to this interviewer.

In addition to the orientations I discovered in talking with respondents and reviewing data, a number of respondents categorized themselves by age. Several female respondents in their late twenties pointed out that they were "more traditional" than some Chinese women in their early twenties. Time did not permit exploring this observation. only one of the study's respondents was a female in her early twenties, and the differences I was able to perceive were related to a poorer command of English and fewer experiences in the U.S. Respondents in their twenties and thirties also spoke about how difficult it was for older Chinese scholars to be in the U.S.--how difficult English was for them, how much they missed their families, how hard it was for them to work long hours (sometimes in restaurants) to support themselves, and how difficult it was for them to adapt to life in the U. S. "The hardest thing particularly for Chinese married scholars is loneliness. I see some who cry--after half a year they want to go back." 
"Some people who visit are older--in their 40's--and it is very hard for them to leave their families and work so hard."

old people [students and scholars visiting the U.S.] is kind of difficult--very difficult. For older people to learn the language is difficult. Most of those older people have more trouble accepting. They say my children would not act like this. (M; $36 ; 5$ years)

Interviews with older (40 plus years) students and scholars confirmed the respondents' observations in terms of the difficulties these "older" Chinese visitors experienced in learning (or communicating in) English.

Although the above categories--those observed by the interviewer and the respondents--are worth noting, they proved to be only marginally useful in terms of describing and interpreting how Chinese students and scholars make sense of interpersonal interaction in the U.S. More important to this understanding are the prominent and prevalent topics and issues that weave throughout the interview transcripts--often across age, gender, and time in the U.S.

\section{TOPICS/ISSUES}

This section highlights individual topics and issues that have emerged in the interviews. It is divided into seven parts. The first, Perceptions of America and Americans, includes generalizations, highly-valued 
characteristics, and troublesome characteristics. The second part focuses on Relationships and includes data on a variety of relationships. The third area is critical Incidents/ Critical Issues. This area includes interpretations by respondents, including the significance of animals in the U.S. and the relationship of education and money. Adaptation, the fourth area focuses on how respondents have changed (or not changed) their thinking and actions over the course of their stays in the U.S. Also, it covers refined understandings and direct and indirect communication. The fifth area, The Impenetrable, deals with confusion and problems which still exist. The sixth area, $\underline{A}$ Chance of a Lifetime, describes the significance a number of respondents place on their opportunity to be in the U.S. The last area, Respondents' Advice to Chinese, reports on the advice respondents would give to newcomers to help them adapt to life in the U.S. The respondent's sex, age, and time in the U.S. are noted at the end of each quotation.

\section{Perceptions of America and Americans}

Generalizations. The generalized view which respondents hold of America and Americans provides a backdrop for understanding their interpretations and actions.

In China we learn that Americans get to know one another very quickly but not too deep. It bothered me sometimes at the beginning; now I'm used to it. I expect it. (F; 27; 8 months) 
Respondents note the prevalence of freedom and independence in the U.S.:

[In the U.S.] If I don't want to, I don't have to. ( $F ; 25 ; 2$ years and 6 months)

I think people can do everything here except for hurting others. (M; 33; 4 months)

Here peoples' concern is how to satisfy themselves without harming others. I don't have to consider--to think too much--about relationships between people and people, between myself and my boss. (M; 27; 1 year and 6 months)

But here [in the U.S.] if you want to do something, you just do it and nobody comes to stop you. (M; 27; 1 year and 6 months)

I think the lifestyles in America are different. Individual freedom. I think individualism is emphasized here. (M; 33; 4 months)

I think Americans have more freedom than Chinese \{in China . ( $F ; 26 ; 3$ years)

Americans direct; they have a lot of freedom. They can do whatever they want. (F; 29;2 years)

There are more chances to improve his ability in the U.S. (M; 51; 4 months)

The following is one example of several where the topic of the prevalence of laws in the U.S. arose:

Most Americans are straightforward; they do not tell lies. They tell jokes. They obey the laws. Law plays a very important role here. If you do something wrong, you will be fined, punished. I believe law here is very powerful, the strongest power here rather than the political leaders or government. (M; 24;9 months)

Americans were frequently described as friendly and helpful (at least if you ask for help): Americans try to give you ideas, help you out, not like chinese. ( $F ; 34 ; 1$ year and 3 months) 
Americans are very helpful. Americans are more friendly. (F; 22; 1 year and 4 months)

American people are very nice. (M; 27; 1 year and 6 months)

Several respondents noted that Americans are more pragmatic than they are intellectual. One expressed his surprise:

I thought Americans very smart because of all the good things Americans make. Things that are made are just wonderful. But people don't seem as smart as I thought. (M; 24; 4 months)

One respondent pointed out differences in privacy:

In china, people do not care whenever they are watched. For example, if they read something, they don't care about others come up and share their reading. Here, in America, I found out that's not the way to act. People feel uncomfortable. When people are doing things by themselves, they want distance. (M; 33; 4 months)

The following are some other ways that respondents perceive America and Americans:

In China most people will talk--gossip; most people don't here. (M; 36; 5 years)

It always seems to me that Americans are together, and they want to talk among them and less things to talk about with me. I feel more things to talk about with Chinese. With Chinese, even if a newcomer, become acquainted with each other instantly. (F; 26; 3 years)

When you are quiet and don't say anything, people will think you know nothing. (F; 25; 2 years and 6 months)

In the U.S., people are much more lonely. (M; 24; 9 months)

We believe Americans are inscrutable. (F; 26; 3 years) 
Characteristics of America and Americans which Respondents Value. Respondents appreciate honesty, religion, independence, hard work, openness, directness, privacy, freedom, and flexibility.

America is very commercial, but people believe in religion and God. Americans are honest and they treat each other honestly. If they don't like it, they say it directly. China, its not very industrialized [although] it's hard to say now. But places like Hong Kong, Malaysia, it is more commercialized. People will try to cheat you in every store at every chance to get your money. I think I really prefer America in this way. (F; 27; 8 months)

I like the independence; we don't have this in China. (M; 24; 4 months)

I like privacy; I like not to owe people. (F; $39 ; 2$ years)

Some flexibility I like. For example in my personal life, I like privacy. (M; 24;4 months)

The systems different and Americans very open and chinese people a little bit too round about. I not really like that. You do not know what they think about. The chinese people very clever, but Americans are also clever and work very hard. ( $\mathrm{F} ; 25 ; 2$ years, 6 months)

Characteristics of America and Americans which Respondents find Troublesome. Many respondents indicated that Americans don't care unless they are asked. Several were troubled about the way jokes were used. Money was an important issue for some students. Divorce and family relationships in the U.S. seemed troubling to many students. One student was troubled by how little American students study 
and many respondents referred to Americans as thinking only of themselves.
When I was first here I was not used to how people make joke about me. Too personal and they make joke and you don't understand what it means because of language problems. We never make jokes unless we're very close--husband and wife or very close friends. When they make joke, it make you feel good. Even now, some- times people make jokes and I don't know how to respond. ( $F ; 39 ; 2$ years)
I think American students play too much; they should pay attention to studying more. I think it is not good for the American future. They only want to think about now--not future. Maybe it's because we live in a Chinese society for a long time and many things force us to think finish studying first and then have fun. Other [things about U.S.] I don't like: just thinking about yourself and not others. Maybe it is because we have too many people in China that we always try not to disturb others. So, in this case, I like China better. (M; 24; 4 months)

\section{Relationships}

During our interview sessions, respondents frequently spoke of relations between spouses, friends, housemates, employers and employees, and others. However, it was not until the post-interview analysis period that it was apparent that an area that could be characterized as relationship was so large. In the process of analyzing and sorting the transcribed interviews, it became clear that well over half the data were in some way related to relationship. As well as general issues of relationship, certain subcategories were prominent: friends, parent/child, housemates, male/female, student/student and student/professor, 
employer/employee, older/younger, and neighbors. This section highlights the individual subcategories of relationship as described or interpreted by respondents.

Friends. As respondents spoke of friendship, they addressed friendship with Americans, friendship with fellow Chinese currently in the U.S., and their general understanding of friendship in China. Although the focus of this research is on how Chinese nationals living in the U.S. make sense of interaction in America, the reader, at times, will find quotations that describe interaction in china. These quotations will be included throughout the Description/Analysis section. They are included because they are an integral part of the respondent's message and often contextualize the respondent's observations. As respondents talk about friendship in the U.S., they describe a highly prohibitive society.

Among same-sexed Chinese, prohibition is prevalent in the U.S. in terms of acceptable physical affection. The following is one of many similar responses:

There was a Chinese student here when I first came. I put my arms around his neck and he said, 'don't do that here, people will think you are gay.' (M; 33; 4 months)

One respondent's view of homosexuals:

After I came here, I have a chance to meet people that are homosexual, and I think they are very nice people, normal, actually better than other friends I meet. ( $M ; 27 ; 2$ years, 6 months) 
Respondents talk about some of the differences in friendship between China and the U.S.:

I've found I have lots of friends here. Sometimes, of course, at the beginning I feel a little bit lonely. of course, I miss that situation in China-you have lots of people around, your friends, you don't have to sit by yourself. Everyone has a lot of things to do [in the U.S.]; it's a disadvantage. But in China, lots of people; not a lot to do, work. You don't need to compete very hard with each other; you relax and enjoy each other. (M; 27; 1 year, 6 months)

Well, making friends is totally different here from China, but I didn't know that. I could talk with somebody for twenty hours and not know much about him as maybe I talk for about five hours with chinese and know a lot about him. Americans don't tell lots of things about private. So, I didn't know that then [when I first came], but I know it now. It's easy to make a friend, but it's not easy to make a close friend. (M; 21; 1 year, 8 months)

Respondents talk about the absence of abundant or completely satisfying relationships in the U.S.:

A friend here help me a lot; help me get settled, everything. Generally, beside that friend, I have a helpful roommate, Chinese. Beside that I cannot find others. No others help me. ( $\mathrm{M} ; 33 ; 4$ months)

Because of language problems--even though they [Chinese] know American friends, they cannot talk as deep. You can only say things like do you like this--do you like that? And after a couple of times you have nothing to talk. If Americans go to China they will have the same problem. Chinese emphasize personal relationships; it's very important. If they do know American friends, it seems not like it was in China. They still want Chinese friends. [Otherwise] you feel lonely and isolated. (M; 27; 1 year, 6 months)

I had plenty of chances to make friends [when I was first here], but I was shy so lots of 
chances that I didn't take advantage of. Sometimes later I thought I should have had a little talking. In china when I met an acquaintance, I just said hi and go away; in America I think I had better stay here and talk a few minutes with them and then go away. A lot of times in china I say hi and go away and in America I think I should have talked with him. I think that's the American way. If they have time I think they would stop and chat for several seconds and then leave. I think that's a better way than in China. You get to know him all the time. Not, for example, you see your friend for only a term then you don't see him. I think two minutes talking improves things; you know him all the time. I think that is because everybody is the same in China. My classmates--I know them without asking them questions. I know him--he's doing that, he's supposed to do that, so he must do that. In America, it's different, everybody doing something different. When $I$ was first here I thought I should not talk and later I learned I should. (M; 21; 1 year, 8 months)

We have host families and go there a lot; we are on very good relationship with them. still it's kind of a superficial relationship. (F; $26 ; 3$ years)

A respondent experiences friendliness from a friend's family and is pleasantly surprised.

Sometimes when my friend invited me to their house, they are very friendly. I don't expect to meet that kind of friendly people. They invite me for birthdays and when they go to the lake, they invite me to go. (M; $23 ; 10$ months)

An issue that was of some importance to respondents who owned cars was how to deal with requests from friends for rides. Although requests by American friends might easily be dealt with on the basis of "American rules" (e.g. if it's convenient), requests by fellow chinese raised questions of which set of rules to use. Do the "Chinese 
rules" of obligation toward chinese friends hold in the U.S.? Or, when in the U.S., should chinese friends accept "American rules"? Respondents sorted this out in different ways:

Sometimes students ask me: will you go to this university? They think this university is only two or three miles away from here, and I say I couldn't do that--it's too far. I find some good excuse; I will not just say no. Sometimes I have to lie to them. I have already made plans and change the subject. I actually lie to them sometimes. If I can do this, I will. But if I can't, I will not. Why spend lots of time? (M; 27; 1 year, 6 months)

Many Chinese friends want to go places and they ask me because I have a car. According to my culture, I cannot say no. Even though I have lots of things to do, study, reading, etc., I can't say no. I wanted to say no, but I couldn't. I'm tired; I have 100 pages to read; I can't say no. I would lose all my friends. still I can't. (F; 39; 2 years)

Another area in which respondents have had to sort out what works best for them is how friendship and money interact in the U.S. Many respondents spoke of their bewilderment when Americans asked them to a restaurant, a movie or someplace else and it seemed impossible to know if the person would pay. They often asked me how they might know beforehand.

The other thing I think is when my friend and I go to dinner. Who is going to pay for the dinner? In the chinese way, only one person pays for the dinner. Sometimes he pays; sometimes I pay. I'd rather do it that way. I've been working in a restaurant for quite a while, and I always see them share up the bill. (M; 23; 10 months) 
When you go to a restaurant in China, he say he pay, I say I pay. Everybody says they'll pay. I feel it's better here. I don't have enough money to pay for everyone; you don't have enough money to pay for everyone; we each pay our own. ( $\mathrm{F} ; 25 ; 2$ years, 6 months)

As a respondent was talking about friendship, he volunteered that: "I'll never ask a person for money if I lend him some. If he remembers, then he will pay me." The respondent was asked what happens if you loan someone money and he doesn't pay you back. "Would you loan him money again and again"? "No, maybe I give him less and tell him I don't have any more." (M; 23; 10 months)

What surprised me about Americans is the way they look at money--very different from me. One [reason] that we don't consider money untouchable is that we always have a small amount of money anyway. It is not the kind of difference for you of $\$ 10,000$ instead of $\$ 100,000$. There is no such difference. We all get $\$ 500$; that's enough. ( $F ; 26 ; 3$ years)

The above respondent talks about her bewilderment when she first came. She had a very kind "friendship family." The woman called her "sweet names" and was very warm with her, however when she asked the family to co-sign with her so she could get a telephone installed, they refused. After having lived in the U.S. for several years, she understands why they did not feel comfortable signing:

I know now there was a kind of danger for them. We suffered later from Chinese students-friends. The case was that my husband and I moved into an apartment and the place where my husband was Iiving was rented by Chinese students. It cost $\$ 37$ to change the name on the phone so my husband said it was okay to leave the phone in his name. He said it was no 
problem. Two years ago the students left and the telephone company called and said the bill was $\$ 481$. He called everywhere. Finally he came back and paid us some money every month. He did finally pay all of it, but that was a lot--a big burden. We cannot trust each other--things like this were taken for granted, but later we realized that that was why our friendship family did that.

The interviewer asked if she helped others out when they had a financial difficulty--like a telephone bill? "Oh, we [in the chinese community] all lend people [in the Chinese community] money. I'm trying to stop doing this." When asked if it is a problem, she said, "No, that guy we had trouble with is very unusual. And my husband used to lend his ID card to let people check out books, and he doesn't do it anymore because we all learned from that experience." The respondent seems to be caught within the inconsistencies that two different rule systems create. Not even within her chinese community in the U.S. is she able to predict which rules are being followed by individual members; therefore, she vacillates between obligations to friends and protecting herself.

Parent/Child. It was in this area that the absence of obligation in American society seemed to trouble respondents the most. It was frequently in disbelief that respondents would refer to American parents who charge their children rent, American children who do not wish to care for their aging parents who are ill or alone, or aging parents who are not highly valued by their children and 
grandchildren. Equally puzzling for respondents was the knowledge that some older people actually prefer to live alone--away from their children and grandchildren.

Why should people send older people away? And now I find that some people prefer to live by themselves. I went to a retirement house in California--it was very good. If they prefer it, it is okay to be alone, but what I worry about is if they prefer to be with their kids and it is impossible. I don't like that. I'm not very happy about that. (F; 27; 8 months)

One thing that struck me is that parents encourage children to do work and get paid. This is striking because in China you are supposed to help your family--you don't get paid for this. Parents [in the U.S.] are polite to their children--treat their kids like friends. Parents in China would be very protective. (F; 27; 8 months)

old people in China live in the family. I don't understand why old people live apart from the family here. old grandma and grandpa have lots of experience and can help you, they can tell the children stories. I don't understand this. (F; 22; 1 year, 4 months)

She's old and retired and alone. That is most surprising to me because family always live together--especially the old folks. And she is watching $T V$ all day long--from morning to evening. She seems to have no place to go. Very seldom [does anyone visit her]. Once a year, maybe, her daughter visits her for a couple of hours. I remember one time her son visited her from out of state. This is very surprising to me because in China the old people are always taken care of by the young kids. (M; 36; 5 years)

They have children, but it is not the relationship that I expect between parents and children. They [parents] rent apartment to their children. stuff like that. That's just unbelievable to us. I think in China parents' and children's relationship is a lot stronger one. That's why they [Americans] can afford to live away from their parents at the age of 18. Chinese do not 
believe this. Before I came at the age of 25 I was still living in my parents' apartment. (F; $23 ; 3$ years)

However, the previous respondent later pointed out:

I left china with the idea that I would go back and live with them [my parents] again. They expect me to do that. But right now, after three years here, I don't very much like the idea of doing that. We have an apartment and can do things.

Although respondents expressed great relief and joy in their escape from obligation in employer/employee relationships, only one respondent spoke about the parent/child relationship in this way:

My husband and I can do everything by ourselves; we don't have to ask for help from anybody. We have each other. It is wonderful--even more than in China. In China he has family; he has to pay some attention to his family, and now he does not have to pay attention to anyone else. (F; 25; 2 years, 6 months)

Housemates. Among respondents there was great diversity in the kinds of people they shared housing with and the experiences they had. However, many respondents seemed troubled by the lack of obligation American housemates feel toward one another and the consequent lack of prohibition.

In the following situation, a respondent $(F ; 27 ; 8$ months) recounts an early experience in the U.S. where her feelings of prohibition were not understood by her host family and both she and the family experienced confusion because of their differing expectations. She did not talk very much to the host couple, but talked to their children. 
They expected me to talk a lot--to be outgoing. I didn't act like that, and I found out they were disappointed. . . In China you should not speak to people who you respect a lot. If they want to talk to you, it's okay.

It appeared from our conversation that the host couple may have been concerned--thinking that her quietness toward them suggested her discomfort or unhappiness. "Actually, I wasn't unhappy. They were working, and how can I bother them"?

This attitude of not wishing to bother others is in distinct contrast to many of the accounts chinese respondents gave of their American roommates' who, like the following American roommate, seemed to believe that if the respondent was bothered by another's actions, it was the respondent's problem:

When one of my roommates had her boyfriend over and made a lot of noise, I told her even though I had put cotton in my ears, I could still hear them. She said I should get a pair of ear plugs. ( $F ; 29 ; 2$ years)

Male/Female. It was in this area of American society --particularly open sexuality--where many respondents seemed to feel real discomfort with the lack of prohibition.

My roommate has a boyfriend. She has only known him one month but they sleep together. She said she had another two boyfriends before. I say you shouldn't do that. But so many people do that. Her boyfriend is a really nice guy. I wanted to warn her about AIDS. She says everybody does it; it's natural. If she really loves someone, she gets married. In China, if a woman is not a virgin, husband will divorce her. In China, girls are very careful. (F; 34; 1 year, 3 months) 
Here in America it's pretty common for boys and girls to put arms around each other and hug and kiss. In china it is not the case--I mean in public. (M; $33 ; 4$ months)

When I came here, I looked for an apartment. I called a number and a boy answered the phone, and $I$ said $I^{\prime} m$ answering an ad for a girl to rent an apartment. He said yes, I'm the one looking for a roommate. I said I can't live with a man. Later, I talked with Americans, and they said, what's wrong with that? [I said] How can you live in the same room, take a bath with a boy. . . A chinese male student told me he had an American roommate and the American roommate went someplace on vacation and told the chinese student that a woman was going to stay in his place and pay the week he was gone. (F; $39 ; 2$ years)

one thing, I met a girl at this school. I felt when girls and boys have contact it just meant friends. A girl I talked to a lot. She think I liked her; I loved her. She knocked on my door, was very aggressive. Later I talked to my roommate and said, I thought American students talk to each other freely so it's okay, doesn't mean anything. She knocked on my door continuously. He said she doesn't have a boyfriend. At last I had to tell her that I didn't mean to lie to her. I have a girlfriend in china, and I have to go back to marry her after my studies. I cannot be more than friends. Now we are friends. (M; 24; 4 months)

Someone came [to our dorm] to talk about how to protect yourself from AIDS. They used a banana and rubber; I just had to leave. (F; 39; 2 years)

The following respondent, a 27 year old, who has been

here about a year and a half, sees some advantages to a

lack of prohibition in male/female relations:

Their [Americans'] relationship--doesn't matter --boys or girls [are] equal. You go to the restrooms, grocery store [and see] signs: safe sex. When they are together, they talk together. We think very bold; they do not care; they talk what they feel--not hide. Lots of terms; they 
talk what they want to talk. If they are not happy with one another, they talk what they feel. For chinese, very quiet. In my classes, lots of times they talk about girls, drinking, and those kinds of things, but we do not talk out about them. In China you say you dated many girls and you say you have more problems; you are looked down upon and blamed. That's not good. It means that if you do that your morality or heart is not good. So that's quite different. I like this way sometimes; you feel comfortable. You express. And also American ways of dealing with one another make you feel more comfortable. If you don't talk what you think, after awhile, it is boring. So very straight is quite different. (M; 27; 1 year, 5 months)

student/Professor and student/student. Since most respondents are in the U.S. to study and/or teach, it is not surprising that important areas of relationship for them are those that center on the classroom. As the data suggest, there appear to be significant differences between a U.S. and Chinese classroom. However, of real interest is how Chinese in the U.S. come to understand these differences and how they deal with them. From the accounts of respondents, it would seem that the expectation of obligation and prohibition figure prominently in the relationship between student and professor. Additionally, the absence of caring relations between professor and students and friendly, cooperative relationships among students seemed disappointing from the chinese students' perspectives:

The way people teach here is different. Here you have more responsibility for your learning. In China professors give very great details-even minor things. If you don't understand, he will go over it. (M; $36 ; 5$ years) 
I think the teacher should take care of both groups. - . The teacher should make sure the others [are taken care of]--not just the two thirds really does well. ( $M ; 21 ; 1$ year, 8 months)

You must stand up to professors. Sometimes you make a mistake and then you say you're sorry; other times you do not, but you must explain that. I'm doing better at that. (M; 36; 5 years)

I find it extremely different here. I study politics and other. I find it much easier to memorize the general ideas here. In China, they rely on the books too much. Here we talk about real things. Creativity here. Not only professor change student, but student changes professor. Professor are very patient listeners. (M; 24; 9 months)

I asked my professor for a recommendation letter and she did not contact me until a week later, and I was a little worried. Students said call her at home, get over your orientalness--push. I said I don't like to push people. I said she is very sensitive, considerate, and she will do it. And she did. (F; 27; 8 months)

I'm more comfortable alone now. In some cases, it is good. For example, if you do an experiment, your professor gives you some details but then you have to decide yourself. Bad thing is that I think people should be more friendly to each other, give each other help. (M; $36 ; 5$ years)

Several students seemed troubled that their professors held the same expectations of them as they did of their American students. Two reasons seemed to surface in the interviews. First, for the Chinese student to gain the same level of understanding as an American required much more time because of language difficulties. Frequently, Chinese students must read notes and reading assignments 
several times to gain comprehension. Secondly, in china,

foreigners are treated specially. Foreign students are

treated with different standards.

One student complained:

You must do the same as American students. So you have to study harder; your social life is limited. (M; 27; 1 year and 6 months)

Difficulties abound for the Chinese scholar who teachs in the U.S.:

In class, at the beginning of the class, I try to make the students to listen carefully, attentively what I was telling them, but they didn't care. But gradually I think this is the way American students act. At the beginning I feel very embarrassed and feel worried about that. They talk to each other; they eat; they drink. Then I realized that's not what I'm teaching is not good, but it's the way American students act. (M; 33; 4 months)

The good thing about the [elementary school] students is that they are very affectionate, very loving. They will hug you again and again and tell you I like you, I love you. They ask me to go to the playground; they ask me how old are you? [They say] You could be our mom. In China, people would be very embarrassed by this to say to a single woman. I know they don't mean harm. On the other hand, students don't respect their teachers as much as in china. The teacher was trying hard to do an average of the numbers and he said, for instance, I give you one hour of homework today, three hours tomorrow, and the class says, 'no way, no way.' I think in China students do not talk back. [Here] the teachers do not mind; they do not care. - . The first day I was so surprised, so amazed. It left such a deep impression. First grade students are so affectionate. You like to do more for them. I think this very good. The Chinese students respect you, obey you, but I don't know if they love you. They may not; it's hard to say. (F; 27;8 months) 
For some students, the absence of communication and relationships among classmates is puzzling and disappointing.

I feel classmates should spend more time to talk about classes, research, etc., but never never can get somebody sit down and talk--not just don't talk with me; they don't talk with anyone. Just in and out which is totally different than China. In China everybody share the same classroom and lots of time together like a school. People just very busy and self-organized and just never try to do things with other classmates. That really out of my expectation. I guess they don't have much time to do that, and it is very difficult for me to invite them to prepare class with them. I begin to feel that's American style so I begin to do these kind of things on my own--unless someone invited me. (M; 27; 2 years, 6 months)

All Chinese students together for four years. They all take the same course. That is not good. They have not much choice for themselves. We do not have much choice. We have to stay together to study. We have a very close relationship; we go for picnic, go to park, we organize parties together. Here that is very difficult because people have different classes even though they study the same thing. Even when they have the same courses, they do not have good communications unless they have studies together for two or more years. I still don't understand; maybe they only know each other a short time--that's why they do not have good communications. (M; 24; 9 months)

I thought people would enjoy to visit each other at home or something. I met a classmate who I took classes with for two or three terms together--the same class. [He was] a very nice guy--neat, study very hard, and he gave me lots of help in class, examination, etc. one day I propose I would really like to visit you and your family. He says, okay--not very enthusiastic. His response totally felt strange. I still remember the way he acted. In China, people are so happy to take people--friends--to visit their family. (M; 27; 2 years, 6 months) 
Sometimes I do pretty good in my class and lots of people ask for my help--especially people from other countries. At that time I had lots of choice: to help him, to help him a little, to help him a lot. Usually I help them a lot because I used to have lots of problems and ask others to help me. I remember that is a hard time when you can't get your homework done when it's due. (M; 2l; 1 year, 8 months)

For others, confusion about appropriate situational behavior between students and professors leads to disappointment and may signal a lack of caring.

I think the most impressive thing about this is that you do not talk business outside of work. sometimes I could not see professors during the day, and they did not seem interested when I talked to them about business at a party. I think it's because business is business. It's not like that in china. I'm thinking maybe it's because they work so hard at work that when they are away they want to relax. Also I think they take things so impersonally. (F; 27; 8 months)

In china, when you are in classes you should be serious, but when you're out, the class is over, the instructor becomes friendly. Here, out of class I act friendly, want to talk to students, but they act like they respect me out of classes. I try to be close to them, but students still look like they respect me. (M; $33 ; 4$ months)

Respondents talk about experiences which made them aware of the differences in student/professor relationships in the U.S. and China. Both seem to find some discomfort in these realizations.

A piece of equipment is broken. I see that the professor is trying to repair it. I should help him repair it if I was in China, but here he says just do your work; I will repair it. In China older people gets more respect. When the interviewer asked if he felt bad when this 
happened, he replied: "Yes, the first time. Now, I don't ask; I just do my work. (M; $36 ; 5$ years)

I think for me to teach here the way I did in China would not be good. It would be forcing them. The class would have a military atmosphere. (M; 33; 4 months)

When asked if the above respondent's students had suggested that, the response was, 'no, they told some others and they told me. It made me feel bad.'

Employer/Employee. Obligation was a central issue in the way respondents talked about employer/employee relationships. On the one hand, respondents expressed disappointment that employers showed so little interest in and concern and respect for them; and on the other, they felt relief from the many responsibilities one has to fulfill to show respect to the boss in china.

At work, usually the supervisor or boss are pretty serious [in China]. You are scared of the boss. Here the boss is pretty funny, acts like young person. People said that's American style. When I go to work, I joke with the boss, and say I don't want to be here, and it's okay. (F; $25 ; 2$ years, 6 months)

The interviewer, in drawing from the previous quotation and others the respondent had made about work in China, asked for confirmation of her understanding of what the respondent was saying. She asked, "From what you've told me, it sounds as though you can joke here about wanting to go home, but then you really have to work; and in China, you can't joke about wanting to leave work, but then you 
wouldn't work--you would read the paper, drink tea, etc. so it's almost like you say it here, but not do it, and in China you don't feel you can say it, but you can do it. Is that correct?" The respondent agreed.

In response to a question about whether the respondent thought others should have helped him prepare for teaching in the U.S.:

Yes, the university, especially the department, should offer more information about students, etc., but maybe that's part of my work--to get used to everything. (M; 33; 4 months)

When foreign teachers come to China, you have a little time to take a shower and take a rest; then there is a banquet for them where they are introduced to all the deans, etc. The next day, someone will show you around the school and show you your classroom, and the third day go around some more. I was expected at the university; they sent me a ticket, but no one met me at the airport. I asked questions, but they only said to read the materials they had given me, and I would get the answer. They said if I had a question I should call them. No one came to tell me how to do anything. If you have a question, they will answer it, but if you don't ask, they will never tell you. (F; 39; 2 years)

Sometimes I'm angry at work. I'm good at the work I do, and I think I should be paid more. Boss ask me to do technical job. I say I can do it because I have five years of work in China. He says he will pay me the same [technical work or regular work]. I feel like he takes advantage of me. I'm so angry I don't want to look at his face. He tells me I do a good job when I begin then he does not say what a good job I do after that. (F; 34; 1 year, 3 months)

Some American students come back from China and say you have to bribe people to get things done. We like this in the U.S. In China we spent lots of time and money to get things done. It makes us happy because we don't have to do these kinds of things here, always thinking what 
the other person is thinking, about your boss. This is good. The worst is when you are working under other people. You have to be very careful with your boss. You spend a lot of time, 60-80 percent, at work to make things look good to your boss. In the states, not so. Some scholars in China still want to do something, but because of the system, it is not happening. But here, if you want to do something you just do it and nobody comes to stop you. I spent half a year to work things out to come here. Also, I have to spend lots of money, buying someone this and someone that. We have a name for this in China, a 'sweet plum.' Here I don't spend anything I don't want. (M; 27; 1 year, 6 months)

Also, I think in the office I'm the director; outside the office, I'm just a friend. Kind of clearcut. I'm not so sure about that. I always have to be careful of the proper time to tell them something. I think it is good to make appointments before you see them and sometimes you need to see someone immediately and then it gets frustrating. Usually I think it's good to arrange life's pace. In china, you just sit there, have a cup of tea, read the newspaper. ( $\mathrm{F} ; 27 ; 8$ months)

older/Younger. The feeling of responsibility and obligation toward the old and young has not easily dissipated for many of the respondents interviewed.

In an interview exchange covering the appropriate course of action to take when blaring radios interfere with the student's ability to concentrate, one respondent said:

Some of the undergrad students turn on the radio, and I don't like it. Some people it doesn't bother, but it is hard for me to concentrate. I think they are kids so I don't complain.

The interviewer asked, "In China, that's how children are treated--be gentle because they are young"? The respondent said "yes." The interviewer queried further, "How do they 
learn if no one criticizes them"? The response, "We'll say something in some opportunity--not right away, but maybe later." (M; 36; 5 years)

As a respondent was talking about things he found notable in the U.S., he reported that, "Sometimes, they [Americans] don't help the handicapped people and older people very much in the U.S. They just do things by themselves. That is very different than in China." When asked if he tried to help a disabled or older person once, he said:

Yes, but they didn't seem to show much. I take the bus all the time, and I find out that not all senior citizens want to sit in seats in the front of the bus which are special for them." (M; 23; 10 months)

Another respondent stated, "In China younger like to help the aged people. That's right. Younger people should help the aged people." (M; 51; 4 months)

Several young female respondents talked about their relationships with women. One talked of difficulties with her roommates, that she is the only person who cleans the apartment, but says "that's probably okay because I'm the oldest." (F; 29; 2 years) Another talks about her close relationship with an older woman she lived with briefly when she first came here. (F; 22; l year, 4 months) She calls the woman "grandma." She talks about her "grandma's" kindness to her. And she talks about her regular visits, to care for "grandma" when she was ill and her special acts 
of kindness toward "grandma." This relationship was obviously very important to the respondent, and was the most significant relationship with an American that was described throughout the interviews.

Neighbors. "[In China] neighbors share food and come over. Here neighbors little contact." (M; 36; 5 years) "If family is happy, harmonious, then the whole society can be something like a good neighbor." (M; 51; 4 months) The respondents who spoke of neighbors frequently mentioned a Chinese saying, roughly translated--"a near neighbor is better than your far relatives." One respondent explains this expression and compares and contrasts her understanding of relations between neighbors in the U.S. and China:

At the beginning, I thought that if neighbors do not know each other, it is awful. Chinese have a saying, a near neighbor is better than your far relatives. If you need help, if you have a sick stomach and your husband is not at home. Who can help you? Your neighborhood. Even if you have relatives 100 miles away, they get there too late--maybe you could die. So a neighborhood is friends. If I'm at home and I see thieves, I will call police. I just thought it was awful not to know even the names of your neighbors. But now, you have your life; I have mine myself, and in a way maybe know each other to say hello to each other and know each other's phone numbers, that's it; and if I'm at home, I don't want other people to know. This is privacy. If I have had a quarrel with my husband, I don't want other people to know. In china all the neighbors know; they ask what happens with you and your husband. I don't want them to know, but they do. We still keep our marriage; we just quarrel. In some ways this privacy is good. You have your privacy; no one bothers you. ( $F ; 39 ; 2$ years) 
General Issues of Relationship. The following comments concern relationships in general and assist us in understanding some of the practical generalizations respondents have made about relationships in the U.S. (F; $26 ; 3$ years)

It always seems to me that Americans are together, and they want to talk among them and less things to talk about with me. I feel more things to talk about with chinese. With Chinese, even if a newcomer, become acquainted with each other instantly. ( $F ; 26 ; 3$ years)

Some respondents were pleasantly surprised to find how helpful and friendly Americans are:

I think the most impressed deeply on me. You ask someone something [in the U.S.], they try to tell you. In China they don't. Here people say good morning to me when I go down the street. ( $\mathrm{F} ; 39 ; 2$ years)

When I first came here I didn't expect so many people to help me. Now I find many people are helpful. If a foreigner in China, not so many people would help him in that way. (M; $21 ; 1$ year and 8 months)

In China we treat foreigners very special. But here we are not; but people have been very nice to me here. ( $M ; 24 ; 4$ months)

I think it is easier to get to know Americans than the English. Americans friendlier. I met an older woman at a shopping center; she asked me if I was from china. She asked me my phone number and address, and wanted me to come to dinner. I never heard from her. (M; 5I; 4 months)

For others an absence of obligation in the U.S. is a relief:

If someone in China invites you to some place, to go to dinner, for a walk, you have to accept them or they will think you don't respect them. 
In the United States this is different. If I don't want to, I don't have to. I like it this way; I like having flexibility. (M; 33; 4 months)

We Chinese act quite differently than Americans; for instance, we think a lot before we do something in China. When new people from China come, we tell them you don't have to carry those burdens where you have to be careful with this person and that person. In China you have to think before you do something. (M; 27; 1 year, 6 months)

But for others the sense of isolation caused by an absence of mutual obligation is troubling:

Now I just feel like I don't give a damn; if you want to know China, go visit. These people want to get as much as possible from you and nothing in return; they don't want to help you do anything. I just got tired of it. (M; 27; 2 years, 6 months)

When people talk with you or play with you, they only spend the time with you they want to spend --just a little time. When you want to continue the talk, go further, they leave. (M; 33; 4 months)

I want to do activities with people, but everyone is busy with his own thing. (M; 24;9 months).

I like Chinese people; they try to help one another. ( $F ; 29 ; 2$ years)

I work at the library and some students were very impatient to see the newspapers. I said they would be ready in one-half hour. They said you had better hurry up because I have to go to class. I was pretty mad. I asked one of the American workers what she would say. She said, 'Wow, they were so rude; I would say, fuck off.' That's something that Americans would do. And I know others that every second word they say is shit or something like that. I worry about that; I don't want to get into trouble with people; to be at odds with others. (F; $26 ; 3$ years) 


\section{Critical Incidents/Issues}

Interpretations. Much like generalizations, interpretations give us a glimpse of how respondents perceive America and Americans. However, interpretations additionally give us the thinking which supports the perception. Interpretations often reveal the practical reasoning which has led respondents to particular beliefs or actions. Interpretations also provide us with respondents' efforts to make sense of situations that are bewildering or troubling:

I think [I should talk longer because] that's the American way; if they have time, I think they would stop and chat for several seconds and then leave. I think that's a better way than in China. You get to know him all the time, not, for example, you see your friend for only a term then you don't see him. I think two minutes talking improves things; [from that] you know him all the time. (M; $21 ; 1$ year, 8 months)

Americans act friendly to me because I am a foreigner and come from china--instead of friendly--just polite and curious. When we talk of friendship, we talk of something that is developed mutually from both sides, and it's a real relationship which can carry on. . . (M; 27 ; 2 years, 6 months)

You don't have a real close relationship here. You are busy; I am busy. We hardly see one another. So it's real hard to start a relationship that is really close--where you can say anything you want with one another. (F; 25; 2 years, 6 months)

Maybe they [handicapped people] don't need help here because they are just ordinary people. (M; 23; 10 months)

American people have a lot of problems; they have to think of only themselves. (F; 29; 2 years) 
They [Americans] do not pay attention because there are so many variety of people in the U.S. so they do not pay much attention to your behavior. ( $F ; 26 ; 3$ years)

Americans get along because they share the same culture. It is hard for them to listen to foreigners because they do not speak so well. It is frustrating for Americans. They are polite but they do not seem to want to listen. (M; 24; 9 months)

I think the U.S. is very proud of itself because it is a very powerful nation, but it does not mean that everyone is clever or intelligent. It seems that those people who are less intelligent are more proud of themselves. (M; 24; 9 months)

- .after awhile you do feel lonely sometimes, and especially chinese people, because they tend to be inside and Americans outside. (M; 27; 1 year, 6 months)

Even though there are thousands and thousands of laws here, people mostly obey them because law plays a very important role here. I find that law is very, very strict. If you do something wrong, you will be fined, punished. I believe law here is very powerful, the strongest power here rather than political leaders or government. (M; 24; 9 months)

Independence is paid so much attention to by everyone. That is why they are isolated. Even though they are with relatives and friends, they are sort of isolated with one another. Lots of people are lonely--lots of people are by themselves. (M; 24;9 months)

When people talk with you or play with you they only spend the time with you they want to spend --just a little time; when you want to continue the talk, go further, they leave. I think that's okay because they have something else to do.

I think because Americans--it's a salad pot-have seen a lot and there are so many Asians on campus around here, they are pretty used to it [the way Chinese act], and I don't think they care a lot either. ( $F ; 26 ; 3$ years) 
Animals. For some newly-arrived respondents, the relationship Americans have with animals is totally bewildering. One respondent in the group interview (M;49;4 months) had kept a newspaper clipping of a dog that had been dressed in baby's clothing. He asked the interviewer if this was a joke. The respondents explained that dogs are illegal in some chinese cities. In the countryside, dogs are kept as protectors of property--they are not for amusement; they have a job. Other respondents seemed to have some ideas about why some Americans have such an intimate attachment to their animals:

The first person I lived with had dogs and cats. The animals had work to do--so she would not be lonely. ( $F ; 22$; 1 year, 4 months)

Americans have dogs to protect them from being harmed by others. Dogs are softer than humans. (M; 28; 5 months)

Education and Money. Several respondents interpreted permissive classroom environments as directly related to students and parents paying for education. One respondent spoke about his experiences with his American students not doing what he told them: "They do not pay attention to what I told them to do so they act in another direction. So I let them go." (M; 33; 4 months) The interviewer asked if he meant that he sent them out.

No, I didn't send them out because I find I cannot send them out because they pay for the class. Students in China do not have to pay for their tuition; the state pays. 
Another respondent makes a similar connection: "Here they [students] can ask any question. It's a different teaching system. Here they pay money to go to school." (M; 36; 5 years) In the following situation the respondent talks about an elementary school: "The school has to be very positive because they are a public school and need money." (F; 27; 8 months)

\section{Adaptation}

Changes Respondents have Observed in Themselves.

Interview data suggest that length of time in the U.S. contributes to respondents' changing interpretations. However, personal motivation and general issues of cultural adjustment appear to be more significantly related to respondents' interpretations and cultural adjustment.

Although changes are noted, to some extent, in other parts of the Description/Analysis chapter, the following are those which respondents spoke of when they were asked directly what changes they had made over the course of their time in the U.S. A number of these changes seem to be related to a sense of freedom of choice.

Well, I always help the poor when I pass by downtown, but I feel there is so many, I just can't afford to give them all so I just pass by. I used to think that people who pass by and don't give anything are bad. I started to do that too. Especially when people talk to me in a drunk way, I don't want to give to them, but I didn't make a distinction before; I just gave to them. (M; 27; 2 years, 6 months) 
In China, if I were invited by someone for dinner, lunch or something like that and they offered me more food, I would say I have enough and that's fine. The first time here I said no, but later I learned if I want more, I must say so. (M; $24 ; 4$ months)

In China, whenever people want to do something, they feel the relationship between him and her and other people; that is the concern. But here people's concern is how to satisfy themselves without harming others, so I act in this way. I make some changes this way. Actually, I made some change. Not in my nature. I still preserve some oriental. I have to make adjustment to this society, to adjust myself to do things well in this society. Sometimes I like to act like Americans; they are very open-minded, they are very honest; they like to talk their own ideas. If they don't agree with you, they say; but they say it in a very polite way. Chinese way, we don't always tell the truth sometimes. We don't want them to feel uncomfortable so we always say good words to them, but that's not good because that not really help him. I like the way of straightforward. (M; 24;9 months)

When I first came here, I thought I could keep myself still in the way I live in China-you know, spend money very carefully and never buy things which are not within my budget. After I came here so many things are so seductive. The first year was okay; I can bear it. The second year, I just can't stop. (M; 27; 2 years, 6 months)

I thought that the International student office should arrange everything. Now I know they have their things to do. In China, everything is arranged by the government--housing, everything. (M; 24;9 months)

When I first here I thought there were so many beautiful girls, now they are less beautiful to me. When I arrived, $60-70 \%$ of women seemed so beautiful; now hardly any woman seems so beautiful. (M; 24; 9 months)

When somebody charge me more, usually I wouldn't say anything because it's not a big deal, but I see most Americans, they do argue about that. Now I do too. When my phone bill is wrong, I 
call the telephone company--even though it's only one or two dollars. (M; 23; 10 months)

People are talking about their divorces very casually--even my teacher. People in China think very serious. But [now I think] not as serious. (M; 23; 10 months)

When I came, I really wanted to go back to china as soon as I finished this course. Now I have changed. It's not that America changed me; China changed me. I just want to stay here for a little longer to see how it comes out in China. ( $F ; 29 ; 2$ years)

At the beginning I thought lots of things people should not do, now I think there are very few-very few should nots. ( $F ; 39 ; 2$ years)

Now days I am very outspoken. I have changed. When you are quiet and don't say anything, people will think that you know nothing.

When I first came here I felt very uncomfortable. Why girls do that, put feet on desk [in the classroom]? But now, I really get used to it. I go into class chewing gum too. I do same thing--put my foot on chair, and ask questions. I do a lot--like Americans. (F; 25; 2 years, 6 months)

I think in some cases I do things [now] and do not worry about others. (M; 24; 4 months)

I asked a lot of questions when I first came here, but I didn't talk a lot. Now I think I talk a lot. (M; 21; 1 year, 8 months)

In china, we do not take shower every day. Here we do take shower every day. If I don't take shower, I will not go out. ( $M ; 24 ; 4$ months)

When I first came here, I thought why should they take bath every day. I'm not that dirty. Now, if I don't take a bath every day, I feel dirty. ( $F ; 25 ; 2$ years, 6 months)

When I first came here, in the cafeteria they put salad in the sandwich, I took it out then; now I leave it in. [In China] we cook everything; we don't like cold vegetables. (M; 24; 4 months) 
When I was first here I was waiting for people to ask me if I needed help, but now I just look around, what is the environment, what is the best way. Whenever I have problems, I help myself. Before that I want to ask people: Do you have some ideas? [Now] I feel myself strong. I think it is better. Secondly, I'm more active. ( $\mathrm{F} ; 39 ; 2$ years)

I'm changing my behavior; I'm trying to be more outgoing. It's kind of hard. (F; 27; 8 months)

When I first lived with sponsors, they were kissing, and I was very embarrassed and turned my head away. One night recently we went dancing with my sponsors. We were kissing, and she said, look at her. Remember when you first came here? ( $\mathrm{F} ; 25 ; 2$ years, 6 months)

At first I was not used to that [the way American students act in the classroom], but gradually it's okay. It depends on you. My responsibility is to teach you something. If you do not listen, that's okay, leave or stay. That is your freedom. (M; 33; 4 months)

No Change. The following are instances where respondents pointedly said they did not wish to change:

I think I should keep my chinese traditional way because that is a way you can concentrate your attention on what your professor tells you. second, is to respect the professor. I think I should keep the chinese way because I benefit from that way. (M; 33; 4 months)

Like how you call your friend's mother or father. You're supposed to call them their name, like Jim. In China, we never do that; I still can't do that. (M; 23; 10 months)

In the U.S. you can say anything you want, but, to me, I still feel like I don't want to say anything. For instance, drug, alcohol--I have very strong feelings about that. I still have. (M; $33 ; 4$ months)

Refined Understandings of U.S. Culture. The following are examples of how respondents often came to refine their 
understanding of America and Americans through direct experience. They seem to recognize that generalizations are inadequate for understanding, and for many rules, there seem to be exceptions:

I think students and American people obey regulations and rules. Students avoid littering. In China many people litter. I thought American people would not litter anywhere but after living here for some time, I realize that some people litter. At the beginning I thought there were no smokers or only a few, but after being here I found student smokers and other smokers. (M; 33; 4 months)

Americans are very friendly and polite. Some of the men I worked with were very rude, though. I think people here can do everything except for hurting others. Before I came here I have the same feeling: American people can do anything they want. Others will not interfere with them. But when I came here, I met people who talk loud and make noise and others act like they cannot do that. (M; 33; 4 months)

Also, I found the same as Chinese--some Americans are intelligent, some are not so intelligent. Some has a good sense of humor and some do not. When I first came here I thought all Americans were the same. (M; 21; 1 year, 8 months)

In most cases, you know, before I came here I think American people are honest people; they obey regulations, university, state, government. After I came here, most of them do the same as I thought, but a few Americans make trouble against these rules and regulations. (M; 33; 4 months)

Sometimes the girls say dirty words. I say, 'Shh.' She says, what's wrong? People look at her like something is wrong. ( $F ; 26 ; 3$ years)

[When I first came] I thought everyone is rich because they own their own house. Now I know it doesn't mean rich. (M; 24; 9 months) 
My host likes to make lots of jokes. For example, sometimes he would make a joke about the rent. He would say something like you are not paying enough rent. I know he's joking, but I think that hurts--that kind of thing. Humor is different. Now, I think he is special in America. Some Americans would not use this joke. Then I was thinking everybody is like him. (M; 2I; 1 year, 8 months)

I was told that you cannot ask lady or girl age or the income of Americans. I asked one lady her age; she didn't mind. They even told me their income. (M; 51; 4 months)

When I first came here I thought everybody used money like crazy and they didn't. Even if they make $\$ 50,000$ a year they still go buy stuff on sale. Americans are thrifty. (F; 25; 2 years, 6 months)

When I first came here I thought I was not supposed to ask others' age. But I think I am asking age of certain people: men, not ladies. When I first came here I thought I was not supposed to ask any questions about age. (M; 21; 1 year, 8 months)

\section{Direct and Indirect Communication: Does "no" mean}

"yes"? For many respondents, one of the earliest things they learned was if you do not assert yourself, you will not be noticed by others. The message is carried in the spoken or written word. As the following respondent says,

Here, if I say no, they think I mean no." [Now] if I wanted something, I would answer yes. In China, I would always say no, even if I mean yes. Here, if I say no, they think I mean no. (M; 23; 10 months)

Suppose someone said your dress is pretty; I'm supposed to say thanks. I didn't know that even though my major was in language in China. I said no, not pretty. In China, you don't say your dress is pretty. ( $F ; 39 ; 2$ years)

If I had some advantage in China, I would not say so, I would not elaborate. When I first 
came here, I was the same; now I would attempt to let others know. If I'm good, really good, I'd say I was really good. The change is because if in China somebody asked me if I was really good, I would say just so so and others would interpret as pretty good. And here, if I say I'm so so, they would think me so so, and if I was really good, they would be surprised. (M; 21; 1 year, 8 months)

I applied to a lot of jobs and I didn't get a job. Someone from my class from the placement office asked to see my resume. She said how are you going to get a job when you don't say anything good about yourself? She wrote all these things; I said they weren't true. She said you have to make yourself look good, look pretty to get a job. ( $F, 39,2$ years $)$

Professor asks a math problem. Sure I know the answer, but I don't want to answer it. Chinese have a way that if you know something, you do not say it. (M; 23; 10 months)

\section{The Impenetrable: Enduring Confusion or Problems}

For some respondents there are ironies in the U.S.

that remain continuing sources of puzzlement. There seem to be situations that defy general patterns: clean, yet dirty; efficient, yet wasteful; open, yet reserved, and so on. One of the more powerful confusions or problems rests with figuring out how to know Americans, how to be close to them.

People put their food on the floor. On the one hand, people are very clean--take shower every day, but then put food on the floor where everyone walks and it is dirty. We don't ever put food on the floor. My roommate throws clothes and shoes everywhere. Sometimes I put them together. My roommate is a little better than others. (M; 24;4 months)

One night I saw some students jump in [puddles of] water on campus. They said this is lots of 
fun; do it. It seemed strange to me. (M; 24; 4 months)

I should make friends with more Americans; I should talk more and have more social activities; I don't know how I can overcome that. I should talk to Americans more, make American friends. They talk a lot. How can I [be] close to them? Another reason I like to have an American friend is that this is a new world for me-there is a lot of things I'd like to know. I should have someone I can ask how to do this; give me some kind of advice so I not make a mistake. ( $F ; 29 ; 2$ years).

I still don't understand in which situation I talk a lot and in which situation I don't talk a lot. In America, when you talk to somebody-different people--you don't talk a lot with some people and you talk a lot with other people. How do you decide? I'm still not sure. (M; 2l; 1 year, 8 months)

That's a problem I still feel is not good. I always wonder what people will think about me, think about my behavior, think about me, but actually they do not take care of [pay attention to] you that much. (M; 24; 9 months)

I thought that everybody hugged each other here. I said, can I give you a hug? She said, I'd feel more comfortable if you don't. (M; 27;2 years, 6 months)

When I first came to live with sponsors, they have friends over and stay there and talk and talk until early morning. Even when they didn't have anything to say, they would stay there and talk and talk. I thought Americans were real efficient. Seemed like they had a lot of time or something. Friends like to come over and sit or something. ( $F ; 25 ; 2$ years, 6 months)

But still when I get to know some Americans, I still have difficulty to find out what to talk to make us closer. I mean in China if I meet some Chinese friend, I can get close to him by raising lots of questions and having him talk a lot of things. In America I still don't know which way I can make him or her talk what is his favorite topic. (M; 21; 1 year, 8 months) 
I work with a lot of these young kids who don't make a call when they are not coming to work. I wonder why they don't since it's so easy to make a call in the U.S. ( $F ; 25 ; 2$ years, 6 months)

\section{A Chance of a Lifetime}

Many respondents described their opportunity to study or teach in the U.S. as "a chance of a lifetime." This saying would often appear after respondents talked about some of the difficulties and hardships of being in the U.S. (being absent from spouse and children, working long hours, struggling to find affordable housing and money for tuition, living with people who were difficult or demanding, spending long hours reading and re-reading course material, spending little, if any, time socializing with others, etc.). Usually, they would say, "but it's a chance of a lifetime." This belief appears to be the justification for any number of hardships experienced in the U.S. It'S as though the addition of this phrase says: This is a rare and precious opportunity to study or teach in the U.S. It is so rare and precious that it makes the worst pain endurable.

As I noticed the phrase being used with some regularity, I referred to it at the end of the remaining interviews if it was not mentioned. Respondents quickly affirmed that that was what being here was: "A chance of a lifetime"! 
Respondents' Advice to Chinese

If there was time at the end of the interview, the researcher asked respondents what was most important for Chinese students and scholars to know to assist their adjustment to the U.S. They felt it was important that they knew they would not be taken care of in the U.S. And related to this, is the importance of being more "active"-not being afraid of doing or asking.

After you come, you should be more sociable. Even the most active person in China is quiet here. Don't be afraid of doing anything, asking things. Some Chinese are afraid of losing face, afraid of asking; they have problems [here]. And also I think if you ask them [Americans] questions, they, most of the time, glad to help you. Most of them very good people. If you don't ask, very hard for them to get to know you. Don't be shy. They [Chinese] also should be accustomed to being lonely for a while. That's a very hard thing for chinese. The hardest thing, particularly for Chinese married scholars, is loneliness. I see some who cry-after half a year they want to go back. If you feel you cannot stand that, you should not come --the misery--you should not leave. (M; 27; 1 year, 6 months)

First, the language. And the more American culture he or she know before coming. Then they can learn and adjust--especially for young people. Old people is kind of difficult. For older people to learn the language is difficult. Most of those older people have more trouble accepting. They say my children would not act like this. ( $M ; 36 ; 5$ years)

They should not expect life here to be like that in China; they should not expect to be taken care of. Americans feel very differently about money; they treat their children much differently than Chinese. (F; 26; 3 years)

Not to be passive in this society; be active aggressive. I try to be that way. In most 
cases I have to depend on myself. (M; 24;4 months)

Everybody cares about his own things, busy with his own things; nobody has time to deal with some others. But [if] you would like to get into contact with them, you must be very active. If you are inactive, they think you are very incapable, even though it is not true. Try to adjust to this society--not just to imitate--to know their character. If you do not know their character, you do not know how to deal with them very well. I still find it is not so easy. I think I have made some changes. I was very afraid to talk in public. You have to be open, expressive to the public. You have to think about those ideas very deeply or you make a fool of yourself. (M; 24;9 months)

PATTERNS: PROHIBITED, OBLIGATED, PERMITTED AND PREFERRED ACTIONS

Schimanoff's (1980) rules scheme was effective in accessing differences in rule expectations. As respondents were asked questions from the Interview Schedule, they responded thoughtfully to most questions. Infrequently, respondents indicated they had had no experience in an area of questioning and, therefore, had no response. When we examine the respondents' "picture" of interaction in the U.S. in terms of understandings of preferred, permitted, obligated, and prohibited actions, some salient patterns emerge.

In terms of preferred actions, we have an opportunity to observe among some respondents, particularly those categorized as "eager to adapt," the refined understanding that 
there is sometimes no "blanket" rule for behavior and a generalization is inadequate in guiding one's actions.

Before I came here I had the feeling that American people can do anything they want. others will not interfere with them. But when I came here, I met people who talk loud and make noise and others act like they cannot do that. (M; $33 ; 4$ months)

Everyone in class is very active. I think I should be like them, [but] sometimes students talk a lot in class; I cannot tell the point. I think the teacher does not always like them to talk so much. (M; 24; 9 months)

When I first came here, I did not know what choice is right or not right; now I'm starting to have some sense of which choice is right for others. For example, I had a roommate who lived with that family. He paid $\$ 150$ for food and rent. He had lunch at school, and he asked the hostess to buy $V 8$ for his lunch every day at school. And I think that's not good any way-not good in China and not good in America. He paid only $\$ 150$ for food and rent and he's asking for more. I think that's a poor choice. (M; 2l; 1 year, 8 months)

In terms of the wide range of permitted behavior in the U.S., some respondents recognize benefits for themselves.

In china, according to chinese custom, women are supposed to be quiet, gentle. Even now, if you are more active--laughing or talking loud--they don't say, but they don't think it's real good. Boy should be boy and girl should be girl. It seemed to me I don't need this; I can think deeply and widely, and if I want to, I should do it. In China, women walk slowly. Sometimes-even though I'm not young, I like to be young and I jump a little. I never had any trouble making friends here. In China, I had a lot of responsibility as a teacher. Here I can act any way I want. (F; 39; 2 years) 
I like the freedom here. People say, would you like to stay in America? I say if I can have a living average--a little bit better than average, I would like to stay. (F; 29; 2 years)

However, respondents sometimes saw the range of permitted behavior in others as exceeding acceptable limits.

[Americans] talk too loud in the library. Chinese people think that you should be considerate. ( $F ; 26 ; 3$ years)

For example, when I want to play pool and someone else is playing, I go away in a Chinese way but Americans just stand behind them waiting. I would be angry because you try to have fun and someone seems to tell you to finish. It's okay if you just look, but if you stand there with a stick, it's not good. (M; 24; 4 months)

If we look at obligated behavior, we find little of it in the respondents' descriptions and interpretations of American behavior. In fact, respondents call our attention to a noticeable absence of it. Some respondents view a lack of obligation as a benefit in particular situations:

There are a lot of things here that are acceptable, so if I don't want to do it, I don't. (F; $25 ; 2$ years and 6 months)

In China we spend lots of time and money to get things done. It makes us very happy because we don't have to do these kinds of things here-always thinking what the other person is thinking, about your boss. This is good. The worst is when you are working under other people. You have to be very careful with your boss. You spend a lot of time--60-80 percent--at work to make things look good to your boss. In the states, not so. (M; 27; 1 year, 6 months)

In china, when you work with your unit--your department--you have to obey everything the department tells you to do, but here in the U.S. there is flexibility. I always find letters, handouts in my mailbox, for instance to announce a meeting or party. You don't have to pay 
attention to that if you don't have time or if you're not interested. But in China, you have to attend the meeting, the party, or people will regard you as an individualist. People criticize individualists. (M; $33 ; 4$ months)

If some Chinese ask me to do something, if I really don't want to do that, if I have class, and they want to go to airport. In China, if they are your friends, you have to miss class and send them to airport. In china, if you do not do this, they will not say something to you, but if later you have something to do, you will have to ask for their help, they will refuse you. If they are relatives, the boss or [people who] work with me, I will have hard experiences. - . But here you just be a friend, be frank and tell; it's okay. But not in China; it's quite different. (M; 27; 1 year, 6 months)

Most often, however, an absence of obligation creates

a greater sense of loss than gain:

The old lady hurt herself, and I think her daughter should take care of her--stay with her mother or take her mother to her home. (M; 36;5 years)

And the relationship between your professor and you is not like in China. In China, it's kind of like family--like parents and child. But here it's kind of like employer and employee. If you need something, you have to say I really need it, otherwise they won't care. (M; 36;5 years)

I hear that American young people have to pay their parents to live at their parents' house. chinese parents always take care of their children. (M; 51; 4 months)

Seems to me that a school should be the professor gives you knowledge. When professor writes a lot of things on the board and I take lots of notes, it seems to me I learn a lot. (F; 39; 2 years)

My roommate, he does not pay the rent; he does not clean the apartment; he is noisy at night and sleeps all day. (M; 24; 9 months) 
Some students do not read; do not prepare for the class. The student does not understand and you have to explain to each one. In China, students prepare. (M; 36; 5 years)

The following respondent is bothered by how little information he was given: "Yes, the university, especially the department, should offer more information about students, etc." He hesitates for a moment, "but maybe that's part of my work to get used to everything." But, then he quickly reasserts his earlier position:

But I think they should provide me with more information about classes, and they did not. If they had provided more information before I teach, I think I would be better." (M; 33; 4 months)

In examining responses in the topic area of relationship, it becomes apparent that the absence of obligation is one of the most disturbing facets of interactive life in the U.S. This fact is further highlighted by the good feelings one respondent has for an American housemate. In contrast to most of the accounts of roommates who show little responsibility toward or obligation to their fellow roommates, the following account carries substantial meaning for the respondent. For the respondent, the housemate's action makes her "feel very good, very comfortable," and she likens this relationship to her family:

My first roommate--she was concerned of me very much. Whenever I am late, she calls me, and she said if ever you're lost, this is your address and phone number. Whenever she leaves, she lets me know where she goes and when she will be back. When I was going on vacation with someone else, she asks me where are you going? She says she has to know because I live in her house and 
if I have trouble, she has to tell my family, my relatives. That made me feel very good, very comfortable. Before I left China, people told me that Americans are emotionless; they only think of themselves, never of others; not always true. This is like when my family leaves, they let me know where they go and when they will be back. ( $F ; 39 ; 2$ years)

The previous account and the following are the only times respondents spoke of relationships with Americans that made them "feel very good." A 22 year old respondent, who has been in the U.S. just less than a year and a half, talks about her close relationship with an older woman she lived with briefly when she first came here. She calls the woman "grandma," and talks about how "grandma" took good care of her when she was first here and how she cared for "grandma" when she broke her arm. She talks about their regular visits and their special acts of kindness toward one another. This relationship was obviously very important to the respondent, and was the most significant relationship with an American that was described throughout the interviews.

In looking at areas where respondents found an absence of prohibition troublesome, we are led particularly to male/female relationships.

A couple asked what I thought about them living together--not getting married. I said if you don't want to get married, don't stay together. ( $F ; 39 ; 2$ years)

one of the girls downstairs had a boyfriend. And when that boyfriend came in, the other girl downstairs--it was like Three's Company. This guy walk along holding two girls. That was very 
shocking to me. For chinese, it is very hard to imagine that your boyfriend will hold another girl at the same time he is holding you. (F; 26 ; 3 years)

Absence of obligation and absence of prohibition blend as respondents talk about their experiences with housemates and student/professor relationships within a classroom setting:

Roommates turn on the radio, stereo. I have a scholarship; I have to get good grades. Next day I had a test; they make lots of noise. They said, I'm sorry, but they didn't turn the noise down. Americans don't seem to think about others--they do their own thing. (F; 34; 1 year, 3 months)

I have one student in my class--talk a lot, and I ask her later why she act this way. She said, we American; this is our class--we act this way. I said, why you choose my class, she said because your class fit my schedule. For me, I think it is okay because it is easy for me to adjust, [but] from our point of view, this is very rude. (M; $27 ; 1$ year, 6 months)

One of the major experiences of respondents was prohibition. Respondents encounter a highly prohibitive interpersonal environment in the U.S. The experience of prohibition ties in with obligation in that respondents are paradoxically prohibited from acting in an obligated way in interpersonal relationships; and, additionally, Americans do not act in an obligated way toward respondents. As the following quotations indicate, many respondents have had experiences which prohibited them from sharing with others, helping others--connecting with others. It is in the area of friendship that prohibition is most acutely experienced. 
In China we have girlfriends and walk around with our arms around their shoulders, but you're not supposed to do that in U.S.; people think you are lesbians. You don't have real close relationship here. You are busy; I am busy. We hardly see one another. So it's real hard to start a relationship that is really close--where you can say anything you want with one another. In China there is more time; not pressure like this. It's a real easy life. (F; 25; 2 years, 6 months)

There was a chinese friend here when I first came. I put my arms around his neck, and he said don't do that here, people will think you are gay. (M; 33; 4 months)

People [in the U.S.] are friendly to me because I am a foreigner and come from china, far away from home and instead of friendly--just politeness and curiosity. I don't feel like that kind of friendliness really exists; and I just misinterpret the politeness and curiosity as friendship. I have a different understanding of friendship. I have a strong sense that I cannot provide other people's needs, so if there is no mutual need, it is hard to have a relationship. Anyhow, sometimes when I sit in the bus I hate to see people around me. Sometimes I feel so weird; I don't know where it comes from. You just have a feeling you don't want to get close to those people. They're Americans and they did nothing to me. I just feel these people around me make me feel--coldness, distance. . . Because when we talk of friendship, we talk of something that is developed mutually from both sides, and it's a real relationship which can carry on. Sometimes I feel that with lots of people they don't want to have a relationship with me--a Chinese, Asian, foreigner. Whenever you get too close, they seem to push you away as though they had nothing to share with you. (M; 27; 2 years, 6 months)

Acting on a feeling of obligation to intervene in an argument or to help a sick roommate, an older person, or a handicapped person, respondents are rebuffed.

Two people are arguing and fighting. In china you have to persuade them to not do that; here 
they don't want you involved. They just want to go till they end it up--maybe until the police come. ( $\mathrm{M} ; 36 ; 5$ years)

In class the professor is looking around for chalk and there is none. In China a student would go right away and get chalk for the professor. I went across the hall and got some chalk and gave it to him. He said thanks. But after class, other students said, why did you do that? I said in China it's the students' responsibility to get the chalk and clean the blackboard. . - The other students said, don't do that; he'll do that. (F; 39; 2 years)

The previous respondent talks about several other times when she tried to help someone: one time was when she knew her roommate had a very bad headache and had gone to bed hours ago. She gently knocked at the door and asked if she could bring her something. The roommate, in a very sharp way, said, "just leave me alone." At another time, she speaks of her experience in trying to help an older woman:

There was an old lady walking down the road; she fell down. I saw this; many people saw this. I offered to help her; she said I'm okay. I couldn't understand why no one help her. She said she's okay like she didn't want me to help.

Lack of Obligation and the Presence of Prohibition as Patterns

Lack of obligation (from others) and prohibition from acting on a sense of obligation (toward others) creates for respondents an interactional life in the U.S. which is characterized by little connection with Americans. 
Behavior which shows a lack of obligation to others or the absence of behavior which acknowledges obligation to others is closely tied with a sense of not caring. Therefore, as respondents observe Americans acting in a nonobligated way, or experience, first hand, relationships where obligation is not present, they feel Americans do not care.

Roommates turn on the radio, stereo, make noise until 12 or 1 am--library closed. I had to put cotton in my ears. I have a scholarship. I have to get good grades. Next day I had a test; they make lots of noise. They said, I'm sorry, but they didn't turn the noise down. Americans don't seem to think about others--they do their own thing. ( $F ; 34 ; 1$ year, 6 months)

[Americans] don't care unless you ask help. They never want to offer unless you ask. (F; $39 ; 2$ years)

Similarly, when respondents are prevented from acting on their sense of interpersonal obligation, they are prevented from showing caring to Americans and prevented from making a connection with Americans.

Once when I was living with a couple, they were quarreling very openly. I heard them. I walked upstairs and said, okay, don't quarrel; what's happened? Come downstairs, sit down, and talk. And they both told me, DON'T INTERFERE. I feel I live there; I should do that; otherwise, what would stop them? They would keep on fighting. (F; 39; 2 years)

For many respondents, obligation in most relationships is seen as something very positive and highly valued--not something to be afraid of or to avoid. Obligation seems to 
be the accepted "glue" for creating and maintaining relationships.

One area in which respondents felt a disturbing absence of obligation from Americans was information giving. It would appear that information giving is strongly associated with obligation. Giving information facilitates knowledge, understanding, and success in others, and it shows caring in the giver. Therefore, a respondent who has to ask for information may feel very hurt or angry; the other must not care about him or her since the information was not freely offered. A respondent points out one of the inherent difficulties in a system where the individual has major responsibility for his or her own grasp of information. When she was asked if Americans were helpful, she said, "If I asked, they were. Some information I don't know--I haven't any idea--so how can I ask"? (F; 29; 2 years)

The giving is relationally binding. Connection occurs through caring for others and for knowing others care for you.

Several respondents point out their understanding that institutional relationships in the U.S. (i.e., professor) student, employer/employee) are governed by a formal exchange of money. Those who pay have more power and unequal power signifies difference and creates distance in relationships. "In the U.S. students pay for their entrance to 
class so they can act in their own ways. The instructors have to act accordingly." (M; 33; 4 months) Some of these respondents express disappointment in the institutional nature of their professor/student relations. They would seem to prefer a personal relationship that is based on a joint relational currency of obligation--one in which information is given freely and caring is understood, more like a relationship with family or friends.

And the relationship between your professor and you is not like in China. In China it's kind of like family--like parents and child. But here it's kind of like employer and employee. If you need something, you have to say I really need it, otherwise they won't care. (M; 36; 5 years)

Patterns of Reasoning and Action: Chinese students' and Scholars' Intercultural Experience

In summary, the various positions respondents have expressed in terms of their experiences with an absence of obligation, suggest a pattern of reasoning that associates acts of obligation with caring. Conversely, the absence of obligated acts is associated with not caring. Therefore, interactions with Americans who do not meet respondents' expectations of obligated behavior (for instance, voluntary information giving) are seen as not caring.

In terms of explaining respondents' actions and the motivation for these actions, the practical syllogism is useful:

A wants to accomplish $\mathrm{X}$

In order to reach $x, A$ must do $1, m, n$, etc.

$A$ sets out to do $1, m, n$, etc. (in appropriate ways) 
For example, a chinese student in the U.S. Wishes to stop an argument between her roommates. In order to stop the argument, she must intervene. She does intervene--attempting to talk them out of arguing. The action of intervening in an argument is appropriate in China, but it is not in the U.S. In China, there is substantial normative force to intervene. In the U.S., however, there is substantial normative force not to intervene. Whereas the goal may be the same (stopping the argument), the means for accomplishing this goal differ in the U.S. and China. The appropriate action or appropriate lack of action required to end the argument are rule-governed and vary from culture to culture.

Within the logic of the practical syllogism we are able to formalize the thinking and action expressed by respondents who participate in intercultural interactions in the U.S. The following chapter examines the significance of this logical structure in terms of the dilemma of non-connectedness. 


\section{CHAPTER V}

\section{CONCLUSIONS}

\section{INTRODUCTION}

In this chapter I first describe some of the dilemmas respondents face in living in a culture where interpersonal "non-connectedness" is highly valued. Non-connectedness as a dominant relational theme is then addressed, with special emphasis on the deviation of women from this dominant theme. Comparisons are made between the interpretations of Chinese students and scholars in this study and the responses of women in Gilligan's (1982) research.

In practical terms, this study may have implications for intercultural training. Specifically, an extensive orientation program is presented which assists in dealing with the lack of interpersonal connection expressed by respondents. Finally, limitations and strengths of this study are presented and future directions are discussed.

\section{DILEMMAS OF NON-CONNECTEDNESS}

The lack of interpersonal connectedness as experienced by respondents presents several dilemmas. One dilemma becomes apparent as soon as respondents arrive in the U.S. 
and, for some, it continues throughout their tenure in America: How to get information necessary to function successfully in the U.S. Another dilemma appears to arise after the initial cultural adjustment has been made. It presents an even more complicated dilemma than getting information: How to know or feel close to Americans. How to relate to fellow chinese in the U.S. became a dilemma for some respondents who had come to understand (and, sometimes, accept) U.S. values and behaviors.

How to Get Information Necessary to Function Successfully in the U.S.

Respondents expect--at least initially--to be given specific information that will help them know what is required of them. They expect to be given information that will facilitate their understanding, their adaptation, and their success. In general, Americans do not volunteer information. As pointed out in Chapter IV, respondents often think of Americans as uncaring because of this.

For those respondents who had responsibility for teaching, the absence of volunteered information was extraordinarily disturbing. All were experienced teachers in China, and they took their responsibility very seriously. However, they were given little, if any, assistance in adjusting to a radically different classroom environment, and, for many, that early period in the U.S. was profoundly painful. 
Initially, many respondents get necessary information from fellow nationals. Some respondents continue to count on chinese peers for most of their "important" information throughout their stays in the U.S. Usually, however, respondents learn that Americans will give information if they are asked. But, then, the respondent is faced with how he thinks and feels about asking questions, and, if he chooses to ask questions, how it should be done.

At the heart of taking responsibility for getting information for one's self (i.e., asking questions) is an individualistic orientation. This is in direct contrast to a collective orientation in which others are expected to give information to you. The data collected from respondents suggest that the way in which they think and act regarding questions may be good indicators of cultural awareness, adaptation and acculturation to the U.S.

First, respondents must realize that question-asking in the U.S. is perceived differently than it is in China. Awareness of this difference suggests the beginning of adaptation in the U.S.

In China, people think it is not very good for a person to always ask questions. With this idea, I did not ask questions. When I came here I found this different; I should ask questions. If you do not know this, and do not know that, go ahead and ask questions. (M; 33; 4 months)

For others, it has become clear that freely asking questions in the U.S. is both appropriate and necessary. 
Respondents ask questions because that's the way things work here. This group has adapted not only to recognizing differences in question-asking, but in acting in accordance with this knowledge.

I think I'm changing now--I'm asking lots of questions. I think that's the way in the American classroom. (M; 21; 1 year, 8 months)

The following respondent seems to feel comfortable asking questions, but still feels that it is not very good for persons to ask many questions. He seems to hold a view which is similar to the way questions are thought about in China. He has adapted to the U.S. in terms of his actions, but not his understanding.

If I keep silent, I think I may never have a chance to ask a question because the others [Americans] are all the time asking questions. (M; 24; 4 months)

Much like the previous respondent, some respondents ask questions when they need information, but still feel some resentment that it is necessary to ask rather than being told. They have learned how to act in an appropriate way in the U.S., but their feelings tell them this is not the way it ought to be. One person (F; 29; 2 years) pointed out that when she first came to the U.S., "Chinese students tried to be very helpful in giving me information." When she was asked if Americans were helpful, she said, "If I asked, they were. Some information I don't know--I haven't any idea, so how can I ask"? For another 
respondent, caring and information-giving are intertwined:

They [Americans] don't care unless you ask.

They never want to offer unless you ask. . . . If you have a question, they will answer it, but if you don't ask, they will never tell you. (F;

39; 2 years).

Some respondents eagerly seek opportunities to ask questions. These respondents have not only accepted question-asking as an inevitable part of life in the U.S., they enjoy having the chance to ask questions freely. They have integrated an "American" way of thinking and acting into their own belief and action systems. In this sense, respondents show evidence of acculturation to the U.S.

When I first came, my English was not as good as now. Sometimes I was afraid to talk to Americans because I could not express myself clear1y. Now, I want very much to talk to many people. Sometimes, on purpose, I ask questions.

(F; 34; 1 year, 3 months)

How to know or Feel close to Americans

Sorting out how to know or feel close to Americans is a bewildering and, at times, painful dilemma for some respondents. They deal with this issue in several different ways.

For one respondent, members of the Chinese university community fill her needs for interpersonal closeness, and although she associates with Americans, she doesn't really expect to know them well or feel close to them. She seems quite comfortable with this situation. Another respondent has American friends and Chinese friends. He enjoys them 
both. However, he points out that friendships with fellow nationals are essential because, "Americans are outside people and Chinese are inside people." (M; 27; 1 year, 6 months) For others, Americans are baffling. Respondents talk about how friendly Americans are, yet it's hard to know what to talk with them about that will interest them or help respondents be close to them. Some respondents seem resigned to this confusion. However, others--often those that seem highly committed to making a life in this society--struggle to find answers to how to know and feel close to Americans. Their efforts are met with minimum success.

Relating to fellow Chinese is, by no means, always a dilemma. Chinese peers provide much support for students and scholars in the U.S. Support systems for money, transportation, housing, friendship, food, and initial "orientations," are only a few of the ways that respondents talked about their fellow chinese.

How to Relate to Fellow Chinese in the U.S.

The dilemma of how to relate to fellow chinese in the U.S. seemed to arise when respondents encountered the collision of two different rule systems for interpersonal interaction. Conflicts often centered on choices between self interest and interest in others. Respondents seemed to struggle between using "U.S. rules" (which emphasize self) 
since they were interacting in the U.S. and "Chinese rules" (which emphasize others) since they were interacting with Chinese. For a few, it wasn't a problem. They simply chose--either "Chinese" or "American," and, generally, interacted with those who were similarly oriented. For others, however, the choices were difficult and, often, the outcome was not without discomfort.

Some respondents avoided interactions with fellow Chinese. Sometimes they talked about this in ways that suggested they wished to follow "American rules," and didn't want to feel pressured to act in a more "Chinese" way. These respondents often wanted very much to become integrated into U.S. culture and, because of this, avoided much contact with fellow chinese.

The three dilemmas described above were prominent as respondents talked about their experiences in the U.S. These dilemmas may not be unique to Chinese students and scholars. Beyond those who are adapting to the U.S. as a foreign culture, there are subgroups within the U.S. who face dilemmas similar to those described by respondents. Gilligan (1982) directs our attention to one of these subgroups: females. She writes about the experience of women in the U.S. where the dominant (i.e., male) interpersonal theme is non-connectedness. 
NON-CONNECTEDNESS: A DOMINANT THEME IN THE U.S.

Gilligan skillfully highlights how prevalent interpersonal non-connection is in the U.S. In her research, nonconnectedness appears as a symptom of a dominant way of thinking and acting. Her studies point out some of the characteristics of this primary orientation: individual achievement is valued over attachment, an identity of separation and power is forged through work, and there is little connection with others (p. 163). The individual orientation is continually rewarded and reaffirmed.

By contrast, a preoccupation with connection--with interdependence--is perceived as weakness. Gilligan's descriptions of womens' thinking are filled with recognition of the significance of relationships and recognition of the highly contextual nature of human life. In these ways, Gilligan's descriptions of women frequently parallel interpretations by chinese nationals in this study. She points out that ". . women not only define themselves in a context of human relationship but also judge themselves in terms of their ability to care" (p.17). She describes the response of one of the women in her studies: "Seeing life as dependent on connection, as sustained by activities of care, as based on a bond of attachment rather than a contract of agreement. . ." (p. 57) In speaking about two women, Gilligan reports, "They both equate responsibility 
with the need for response that arises from the recognition that others are counting on you and that you are in a position to help" (p. 54). Once again, the significance of care and interdependence are emphasized:

This ethic [of care], which reflects a cumulative knowledge of human relationships, evolves around a central insight, that self and other are interdependent. (p. 74)

Gilligan's female respondents gave much attention to the words caring, responsibility, relationship, connection, and interdependence. Similarly, Chinese respondents in the present study gave much attention to these same words and concepts.

The major emphasis of Gilligan's book is to point out that major western psychological theorists have posited theories of moral development that ignore the importance of ways of thinking which emphasize relationship, interdependence, and equity--areas which have been considered primarily a female domain. Instead, individualism, equality and laws are the accepted paths to "moral development." Gilligan talks about the power of relationship in ending this lack of connection:

The experience of relationship brings an end to isolation, which otherwise hardens into indifference an absence of active concern for others, though perhaps a willingness to respect their rights. ( $p$. 163)

Gilligan stresses that women, because of their ways of thinking, are often outside this primary view of the social 
world. And in forging their identities, women often struggle between their unsanctioned view of the way life should be--enmeshed in a web of connection--and the dominant view of social Iife which de-emphasizes relationships and depends on laws for social order. It would seem, from the accounts of chinese students and scholars in this study, that they encounter a similar devaluation of connection in the U.S. and, perhaps for some, a crisis of identity. If we accept, in general, that U.S. females and Chinese nationals in the U.S. share a similar orientation toward relationships, perhaps Chinese can enlist some strategies that American women have used to create a fulfilling sense of interpersonal connection in their lives.

\section{IMPLICATIONS FOR INTERCULTURAL TRAINING AND ADVISING}

Assisting students and scholars in fulfilling their needs for interpersonal connection is one important area of intercultural training and advising. I have identified women as a subgroup that may be able to offer relevant strategies for adaptation. However it is likely that there are experiences of other subgroups in the U.S. that may also be able to offer practical strategies for interpersonal connection and adaptation. I am suggesting that there are some experiences which visiting chinese students and scholars share not only with fellow Chinese and other foreign students but with subgroups who permanently reside in 
the U.S. The collected experiences and adaptation strategies of these "residing subgroups" are sources of information that can supplement programs which orient the visiting Chinese student and scholar. Additionally, members of certain "residing subgroups" may provide an interpersonal bridge between valued beliefs and the dominant orientation in U.S. culture--an orientation which emphasizes the individual and remunerated work.

\section{orientation Programs}

Orientation programs often come in several forms and serve several functions. Information is frequently offered on practical matters, on characteristics or facets of a particular culture, or on general issues relating to adjustment to any new culture. The purposes of orientation programs vary. Sometimes basic information-giving is the major goal. Some orientation programs provide many opportunities for face-to-face intercultural contact, assist with personal and professional adjustment and serve as an opportunity to welcome foreign nationals. orientation programs are sometimes offered to sojourners before they arrive in the host country, within days of arrival, and, occasionally, two to three months after arrival.

Most often, international students and scholars participate in one "initial orientation" that minimally gives information and, ideally, may serve all of the functions 
listed above. There is rarely a pre-departure orientation or a "followup" orientation after two or three months. Brislin (1981) points out that,

The preparation of people for their first crosscultural experience continues to be a difficult task. One promising approach is to orient sojourners after they have lived in another culture for two or three months. By that time, they will have had experiences which need explanations. . (p. 105)

The ideal orientation schedule would include three parts. First, a pre-departure orientation would consist of both culture-general training (how values affect behavior and consequent attributions of "good" and "bad") and culture-specific training (norms, values, and behaviors prevalent in the host country). During this orientation session, there would also be many opportunities for informal discussions between chinese students and scholars and American nationals.

secondly, an orientation several days after the arrival of the students and scholars in the U.S. would consist of practical information necessary to functioning in the University and local communities. Additionally, the orientation would provide professional and social interpersonal contacts (initial people who will act as intercultural interpreters). And, very importantly, the orientation would provide an enthusiastic welcome from the university and local communities--a welcome that openly endorses and 
makes a commitment to interpersonal exchange and continuing relationships.

The followup orientation several months after arrival has one of the most significant functions. This orientation focuses on culture-general training. However, culturespecific characteristics are also addressed, with special attention to the situational/historical background which influences these characteristics. Perhaps, most importantly, this orientation must provide opportunities for students and scholars to discuss areas of confusion, anger, surprise, relief, joy, etc. Therefore, the emphasis is less information-giving than discussion. The group, if it is large, should frequently be divided into small-group discussion sections and this orientation session should discuss the value of support groups and provide resources (including face-to-face contacts for these groups). When students leave this session, they should know they have at least several "cultural interpreters" they can talk to about personal or social issues which they find bewildering in American culture. Additionally, college and university international education staff act as consistent "official" cultural advisors throughout the students' and scholars' academic sojourn.

From the findings in this study, chinese students and scholars feel that Americans are not interested in them, are not caring people, and, as a result, do not provide 
them with information necessary to adequately function--at least initially--in the U.S. The orientation schedule outlined previously gives information relevant to the visiting student and scholar. Additionally, the ongoing commitment that this orientation schedule provides suggests caring on the part of Americans. Additionally, the interpersonal contact that is emphasized in small groups, individual contacts, and recognition of the contribution students and scholars make to Americans' understanding and knowledge suggests that these visitors are highly valued and cared for.

The orientation's commitment to culture-general and culture-specific training, and efforts to insure the accessibility of "cultural interpreters" indicates a commitment to assisting students and scholars in understanding U.S. culture--not simply surviving American life. The orientation additionally provides face-to-face formal and informal contacts with people who are involved in fellow-national groups (i.e., Chinese student and Scholar Associations) and groups which emphasize involvement with Americans and U.S. culture (i.e., host families, speaker's groups, ChineseAmerican Friendship Associations, etc.). Just as members of some ethnic groups and many women in the U.S. have discovered, it is psychologically essential to form friendships and associations that give credence to personal and cultural values which are not espoused in mainstream American society. 


\section{LIMITATIONS OF THIS STUDY}

In most cases, there was only one interview session with each respondent. It would have been very helpful to have at least one more session. This would have made it possible to follow up on statements that were not fully elaborated during the first interview. To some extent, statements that were not fully developed might have more frequently been probed by a more experienced interviewer. As the interviews progressed, I was able to identify more statements that required further questioning, however, even in the later interview transcriptions, I found some areas that would have benefited from further probing. In-depth interviewing is a practiced skill, and my limited experience in this area was a shortcoming.

one third of the respondents had been in the U.S. four months or less when they were interviewed. This may have been too brief a time to adequately address the questions that were asked in the study, particularly those related to change. Since the language skill of most of these respondents was minimal, it was very difficult for them to understand the questions adequately to provide rich, complex responses. Therefore, with the exception of several respondents, most of the interview data comes from the remaining two thirds of the sample. 
Finally, the respondents were drawn from a limited geographical area. Given the localized nature of the sample, it is possible that there are characteristics of this group which are unique to the region.

STRENGTHS AND BENEFITS OF USING NATURALISTIC RESEARCH METHODS

Despite the limitations of this study, the depth and range of information collected from respondents was substantial. In major part, this was related to the choice of indepth interviewing as the method of data collection.

Respondents were eager to share information about themselves. After our interviews, respondents frequently said they had really enjoyed talking with me. One international student advisor told me that one of her students thanked her for recommending that I talk with her. She said the student was very surprised that a research interview "was so nice." The student had said, "It was like talking to a good friend." At the end of one interview, a student suggested I should go into personnel work because I was "so nice to talk to," and another student suggested I was "like a Chinese mother."

These comments may simply be kind or polite words on the part of the respondents; however, I believe they suggest something more. First, I think the respondents had ideas and feelings they wanted to talk about, and often 
times, had little opportunity to do this. A number of respondents in this study talked about Americans not offering information or Americans not asking if respondents had questions. Second, by gathering information through faceto-face contact, in a fairly informal, personal way-allowing the respondent to talk about what was most important to him or her--the respondent felt like a person who someone was interested in, not like a number or object that someone wanted to get information from, with little care about the person who provided it. Finally, data from this study suggests that many respondents lack warm interpersonal relationships with Americans. Perhaps my willingness to sit and talk and listen--usually as long as respondents wished--was something that was rare for them.

Another benefit that arises from the range and depth of information collected in this study is the opportunity to corroborate, test, or challenge world view I research within a richly contextual matrix of respondents' interpreted experience. The data also provided an informal testing ground for the relevance of Hall's concept of high- and low-context cultural experience. The usefulness of a rules approach in understanding interaction as a cultural experience was confirmed.

An additional benefit of the depth and range of information offered by respondents was that categories, themes, 
sayings, and so on, were repeated many times providing a substantial degree of confidence in the results.

\section{FUTURE DIRECTIONS}

Friendship was a very important issue for many of the respondents in this study. It would be valuable to regularly meet with Chinese students and scholars during their tenure in the U.S. (or, perhaps, during their first two years) to gather understandings of friendship with Americans and fellow chinese and the prevalence and depth of these relationships. Additionally, a longitudinal study could be useful in exploring the following finding from this study: Personal motivation and general issues of cultural adjustment appear to be more significantly related to respondents' interpretations and cultural adjustment than does length of time in the U.S.

An important area which needs to be explored is the experience of Chinese who teach in the U.S. Respondents in this study were very troubled about their lack of initial information, orientation, support, and consequent performance as teachers during their early months in the U.S.

An additional area of relevant research is the adjustment and acculturation process of chinese students and scholars who are highly motivated to remain in the U.S. Some of these students may be attracted to the U.S; others may be reluctant to return to china. Somewhat related to 
this research is an exploration of chinese students' and scholars' interpretations of why they are in the U.S. and why they wish to stay or return to China.

An area of research that I believe is important to our understanding of chinese women is the exploration of female students' and scholars' experience in the U.S. Additional1y, research related to our understanding of families could be gained from Chinese students and scholars who are in the U.S. While their spouses or children remain in china. 
REFERENCES

Agar, M.H. (1980). The professional stranger: An informal introduction to ethnography. New York: Academic Press.

Alexander, A., Cronen, V. Kang, K., Tsou, B. \& Banks, B.J. (1986). Patterns of topic sequencing and information gain: A comparative study of relationship development in Chinese and American cultures. Communication Quarterly, 34 (1), 66-78.

Bellah, R.N., Madsen, R., Sullivan, w.M., Swidler, A., Tipton, S.M. (1986). Habits of the heart:

Individualism and commitment in American life. New York: Harper and Row.

Berger, P.L. and Luckmann, T. (1967). The social construction of reality. Garden City, NY: Anchor Books.

Barnouw, V. (1973). Culture and personality. Homewood, IL: The Dorsey Press.

Bond, M.H. (Ed.). (1986) The psychology of the Chinese people. Hong Kong: Oxford University Press.

Brislin, R. (1981). Cross-cultural encounters: Face to face interaction. New York: Pergamon Press.

Casmir, F. (1983). Phenomenology and hermeneutics: Evolving approaches to the study of intercultural and international communication. International Journal of Intercultural Relations, 7, 309-324.

Coleman, J.S. (1958). Relational analysis: The study of social organization with survey methods. Human organization, 17 (4), 28-36.

Cushman, D.P. (1977). The rules perspective as a theoretical basis for the study of human communication. Communication Quarterly, 25 (1), $30-45$. 
Cushman, D.P. \& Pearce, B.W. (1977). Generality and necessity in three types of theory about human communication with special attention to rules theory. Human Communication Research, 1 (4), 344-353.

Dernberger, R.F., Dewoskin, K.J., Goldstein, S.M., Murphey, R., \& Whyte, M.K. (Eds.) (1986). The Chinese: Adapting the past, building the future. Ann Arbor, MI: The University of Michigan Center for Chinese studies.

Ehrenhaus, P. (1983). Culture and the attribution process: Barriers to effective communication. In $W$. B. Gudykunst (Ed.), Intercultural communication theory: Current perspectives (pp. 259-270). Beverly Hills: Sage Publications.

Geertz, c. (1973). The interpretations of culture. New York: Basic Books, Inc.

Gilligan, C. (1982). In a different voice: Psychological theory and women's development. Cambridge, Massachusetts: Harvard University Press.

Glaser, B.G. \& Strauss, A.L. (1967). The discovery of grounded theory: strategies for qualitative research. New York: Aldine De Gruyter.

Gudykunst, w.B. (1983). Uncertainty reduction and predictability of behavior in low- and high-context cultures: An exploratory study. Communication Quarterly, 31 (1), 49-55.

Gudykunst, w.B. \& Nishida, T. (1986). Attributional confidence in low-and high-context cultures. Human Communication Research, 12 (4), 525-549.

Hall, E.T. (1976).. Beyond culture. Garden City, NY: Anchor Press/Doubleday.

Hawes, L.C. (1977). Toward a hermeneutic phenomenology of communication. Communication Quarterly, $\underline{25}$ (3), 30-41.

Hofstede, G. (1980). Culture's consequences: International differences in work-related values. Beverly Hills, CA: Sage Publications.

Hsu, F.L.K. (1981). Americans and Chinese: Passage to differences (3rd ed.). Honolulu, HI: The University Press of Hawaii. 
Hsu, F.L.K. (1983). Rugged individualism reconsidered: Essays in psychological anthropology. Knoxville, TN: The University of Tennessee Press.

Institute of International Education. (1988). open Doors. New York: Author.

Kim, Y.Y. (1985). Communication and acculturation. In L.A. Samovar \& R.E. Porter (Eds.), Intercultural communication: A Reader. Belmont, California: Wadsworth Publishing Company.

Lincoln, Y.S. \& Guba, E.G. (1985). Naturalistic inquiry. Beverly Hills, CA: Sage Publications.

Littlejohn, S.w. (1983). Theories of human communication. Belmont, $\mathrm{CA}$ : Wadsworth Publishing Company.

Liu, 2. (1984). Two years in the melting pot. San Francisco, CA: China Books and Periodicals, Inc.

Lofland, J. \& Lofland, L. (1984). Analyzing social settings: A quide to qualitative observation and analysis. Belmont, CA: Wadsworth Publishing Company.

Marsella, A., DeVos, G.W., \& Hsu, F. (Eds.) . (1985). Culture and self: Asian and western perspectives. New York: Tavistock Publications.

Mccall, G.J. \& Simmons, J.L. (1969). Issues in participant observation: A text and reader. Reading, MA: Addison-Wesley Publishing Company.

Mischel, T. (1969). Human action. New York: Academic Press.

Munro, D. (Ed.). (1985). Individualism and holism: Studies in Confucian and Taoist values. Ann Arbor, MI: The University of Michigan.

Nakamura, H. (1964). Ways of thinking of eastern peoples: India-China-Tibet-Japan. Honolulu, HI: East-West Center Press.

Okabe, R. (1983). Cultural assumptions of east and west: Japan and the United States. In W. Gudykunst (Ed.) Intercultural communication theory: current perspectives (pp.21-44). Beverly Hills, CA: Sage Publications. 
orleans, L. A. (1988). Chinese students in America: Policies, issues and numbers. Washington, D.C.: National Academy Press.

Perry, R. (1949). Characteristically American. NY: Alfred A. Knopf.

Philipsen, G. (1977). Linearity of research design in ethnographic studies of speaking. Communication Quarterly, 25 (3), 42-50.

Pilotta, J.J. (1983). The phenomenological approach. In W.B. Gudykunst (Ed.), Intercultural communication theory: Current perspectives. (pp. 271-282). Beverly Hills: Sage Publications.

Rapson, R. (1967). Individualism and conformity in the American character. Lexington, MA: D.C. Heath and Company.

Shimanoff, S.B. (1980). Communication rules: Theory and research. Beverly Hills, CA: Sage Publications.

Stewart, C.J. \& Cash, W.B. (1988). Interviewing: Principles and practices. Dubuque, Iowa: Wm C. Brown Publishers.

Stewart, E.C. (1972). American cultural patterns: A cross-cultural perspective. Yarmouth, ME: Intercultural Press.

Taft, R. (1977). Coping with unfamiliar cultures. In. N. Warren (Ed.), studies in cross-cultural psychology. Vol. I. London and New York: Academic Press, 1977.

Taylor, S.J. \& Bogdan, R. (1984). Introduction to qualitative research methods: The search for meanings. New York: John Wiley \& Sons.

Wang, T. (1986). The American kaleidoscope. (L. Guan, Trans.). Beijing, PRC: New World Press.

Yao, E.L. (1983). Chinese students in American universities. Texas Tech Journal of Education, 10 (1) 35-43.

Yeh, E. (1976). Cross-cultural adaptation and personal growth: the case of chinese students. Acta Psychologica Taiwanica, 18, 95-104. 
Yoshikawa, M. J. (1987). Cross-cultural adaptation and perceptual development. In Y.Y. Kim and W.B. Gudykunst (Eds.) Cross-cultural adaptation: current Approaches. Newbury Park: Sage Publications. 
APPENDIX A

LETTER TO POTENTIAL RESPONDENT 
I am a graduate student at Portland state University in Intercultural Communication, and am currently writing a thesis on how Chinese nationals living in the U.S. interpret interactions with Americans, and how these interpretations may change over the course of their stays.

I am interested in interviewing students and scholars from the People's Republic of China who are visiting oregon colleges and universities. Your international student advisor suggested you might be interested in participating in this study.

The interview takes approximately an hour and I would arrange to do it at a time and place that is convenient for you. I hope to complete the interviewing within the next several months.

If you have questions or are interested in meeting with me, would you be kind enough to write your address and telephone number on the enclosed card and return it to me. I'll then contact you to answer your questions or to arrange a convenient meeting time.

I hope you'll decide to be a part of this study. I'm looking forward to meeting you.

Best wishes,

Donna McElroy 
APPENDIX B

INTERVIEW SCHEDULE 
Primary Questions:

I. OBLIGATION "should"

Think back to your early experiences in the U.S.

Tell me about those times when your impulse was to act in a certain way, but you just weren't sure that you should.

Tell me about those times when you thought you should act in a certain way, and you did, and it turned out fine.

Tell me about those times when you thought you should act in a certain way, and you did, but you were wrong.

Tell me about those times when you thought others should act in a certain way, but they did not.

Tell me about those times when you thought others should act in a certain way, and they did.

In what ways have you changed in the way you think you should act?

In what ways have you changed in the way you think others should act?

II. PROHIBITION "should not"

Again, please think back to your early experiences in the U.S.

Tell me about those times when your impulse was that you shouldn't act in a particular way, but you just weren't sure your impulse was correct.

Tell me about those times when you thought you should not act in a particular way, and you did not, and it was fine.

Tell me about those times when you thought you should not act in a particular way, and you did not, but you really should have.

Tell me about those times when you thought others should not act in a particular way, but they did.

Tell me about those times when you thought others should not act in a particular way, and they did not. 
In what ways have you changed in the way you think you should not act?

In what ways have you changed in the way you think others should not act?

III. PERMISSIBILITY/PREFERABILITY

once again, please think back to your early experiences in the U.S.

Tell me about those times when you thought you could act however you really wanted to, and you did, and it was okay.

Tell me about those times when you thought you could act however you really wanted to, and you did, but you were wrong.

Tell me about those times when you thought others could act however they wanted to, but when they did, it was clear they shouldn't have.

Tell me about those times when you thought others could act however they wanted to, and when they did, it seemed to be okay.

Think about those situations where you feel you have a lot of flexibility to act however you want.

In what ways have you changed in the way you think about those situations?

In what ways have you changed in the way you act in those situations?

Think about those situations in which others seem to have a lot of flexibility to act however they want.

How have you changed in the way you think about the actions others choose. 
classroom (teachers, students) social occasion (formal, informal)

church

family/roommate (living situation)

meals

greetings/farewells

first meeting

speaking/not speaking

friend/acquaintance

conversation topics (family, friends, home country, romance, etc.)

interactions with different-aged persons (children, older adults, peers, adults of parents' age)

when you or someone else encounters a problem

when you or someone else is evaluated (complimented, criticized)

*The follow up categories are ordinary life activities. The

follow up categories supplement the primary questions. They act as more specific situational probes so that questioning in depth is possible.

Additionally, as interviewing progresses, it is likely that salient issues will arise necessitating additional areas of probe within the Interview schedule. 
APPENDIX C

INFORMED CONSENT 
I,

hereby agree to serve as a respondent in the research project entitled, "Interpretations of Interaction in the U.S. by Chinese Nationals: A Phenomenological Analysis conducted by Donna McElroy under the supervision of Peter Ehrenhaus, Ph.D.

I understand that the study involves verbally responding to questions asked by Donna McElroy.

It has been explained to me that the purpose of the study is to learn how Chinese nationals think and feel about the way in which people interact in the U.S.

I may not receive any direct benefit from participation in this study, but my participation may help to increase knowledge which may benefit others in the future.

Donna McElroy has offered to answer any questions I may have about the study and what is expected of me in the study. I have been assured that all information I give will be kept confidential and that my identity will be protected in any discussion of results or in any written research summary.

I understand that I am free to withdraw from participation in this study at any time without jeopardizing my relationship with Donna McElroy, persons who may have referred me to this study, Portland state University, or the college or university I am attending.

I have read and understand the foregoing information.

Date

Signature

If you experience problems that are the result of your participation in this study, please contact the secretary of the Human subjects Research and Review Committee, office of Grants and Contracts, 303 cramer Hall, Portland state University, 464-3417. 


\section{APPENDIX D}

FACE SHEET 
Date of Interview

Place/Time

Age

Sex

Educational

Institution

Field of study

Period of Time in U.S.

Live with U.S. citizens?

How

Long?

Work with U.S. citizens?

How

Long?

Is it okay to contact you for a second interview?

Are you interested in receiving results of this study?

Respondent known to investigator before this interview? 